\title{
Evaluation of ceramic candle filters degradation and damage location using four-point bending tests
}

\author{
Wu Tseng Peng \\ West Virginia University
}

Follow this and additional works at: https://researchrepository.wvu.edu/etd

\section{Recommended Citation}

Peng, Wu Tseng, "Evaluation of ceramic candle filters degradation and damage location using four-point bending tests" (1999). Graduate Theses, Dissertations, and Problem Reports. 1047.

https://researchrepository.wvu.edu/etd/1047

This Thesis is protected by copyright and/or related rights. It has been brought to you by the The Research Repository @ WVU with permission from the rights-holder(s). You are free to use this Thesis in any way that is permitted by the copyright and related rights legislation that applies to your use. For other uses you must obtain permission from the rights-holder(s) directly, unless additional rights are indicated by a Creative Commons license in the record and/ or on the work itself. This Thesis has been accepted for inclusion in WVU Graduate Theses, Dissertations, and Problem Reports collection by an authorized administrator of The Research Repository @ WVU. For more information, please contact researchrepository@mail.wvu.edu. 


\title{
EVALUATION OF CERAMIC CANDLE FILTERS DEGRADATION AND DAMAGE LOCATION \\ USING FOUR-POINT BENDING TESTS
}

\author{
Wu Tseng Peng \\ Thesis Submitted to the College of Engineering \\ At West Virginia University \\ In Partial Fulfillment of the Requirements for \\ The Degree of Master of Science in Engineering
}

Roger H. Chen, Ph.D., Chair

Bruce Kang, Ph.D.

Eric Johnson, Ph.D.

Department of Mechanical Engineering

Morgantown, West Virginia

1999 


\section{ABSTRACT \\ EVALUATION OF CERAMIC CANDLE FILTERS \\ DEGRADATION AND DAMAGE LOCATION USING FOUR-POINT BENDING TESTS}

\section{Wu Tseng Peng}

The structural integrity of ceramic candle filters is a key element for hot gas cleanup systems. Ceramic candle filters used in demonstration plants have experienced degradation and fracturing. Preliminary examination of these ceramic filters indicated that damage of the filters may have resulted from strength degradation due to persistent high temperature operation, thermal transient events, excessive ash accumulation and bridging, and pulse cleaning. This study proposes a nondestructive evaluation of the structural properties of these ceramic filters. The ceramic candle filter is a slender structure made of layers of porous materials. The structure has high acoustic attenuation, which has greatly limited the conventional acoustic emission or acoustic-ultrasonic detection capability. A virgin Refractron filter and twelve Schumacher filters which were previously tested under high pressure and high temperature at a demonstration power plant were evaluated. The acoustic signatures of the ceramic filters are established using a transient impact response technique. Results indicate that the natural frequencies of the filters can be used as an index to quantify the damage condition of the filters (Chen and Parthasarathy, 1996).

In order to confirm the dynamic response analysis, bending tests were performed to estimate the Young's modulus from the load-deflection curve and compared the results with the predicted values from vibration analysis. Four-point bending tests were conducted on seven intact filters, which included five used Schumacher filters, one new Schumacher filter and one new Refractron filter. Each ceramic candle filter was subjected to an applied load up to $40.7 \mathrm{lb}$. and the center deflection was measured using a digital transducer. The deflection was used to reflect the stiffness of ceramic filters. The bending test results can reflect the change of the stiffness among these filters and this change of stiffness matches with the observation from the vibration tests. To measure the deflection of ceramic candle filters one should conduct the tests in a quiet environment. Any small tremble will lead a large difference between theoretical and experimental results. 


\section{ACKNOWLEDGEMENTS}

I would like to thank my research advisor and committee chairman, Dr. Roger H.L. Chen, for providing guidance and motivation throughout the course of this project. Appreciation is also extended to the other members of my committee, Dr. Bruce Kang and Dr. Eric Johnson, for reviewing this work and providing helpful suggestions.

Also, I must express my appreciation to Dr. T.K. Chiang and Dr. Paul Yue from the Department of Energy at Morgantown Energy Technology Center, for their financial support under the contract No. DE-AP21-96MC29319, and valuable comments during the course of the study. I would like to thank Mary Anne Alvin of Westinghouse Electric Corporation, Science and Technology Center and Richard Dennis of DOE/METC for their help in providing the used Schumacher Dia Schumalith filter specimens. I want to thank Shen-En Chen and Balaji Parthasarathy for their contributions and assistance.

Finally, I would like to thank my family and Fr. Simon Yi for motivating me to work hard toward completing this work. 


\section{TABLE OF CONTENTS}

$\begin{array}{lll}\text { ABSTRACT } & \text { ii }\end{array}$

ACKNOWLEDGEMENTS

LIST OF TABLES vii

LIST OF FIGURES - ix

Chapter 1. INTRODUCTION - ---------------------------------------- 1

1.1 Introduction 1

1.2 Objectives 2

1.3 Scopes 3

1.3.1 Literature Review 3

1.3.2 Non-Destructive Evaluation studies 3

1.3.3 Damage Analysis 4

1.3.4 Bending Test and Analysis 5

1.3.5 Numerical Studies $\quad 5$

$\begin{array}{lll}1.4 & \text { Organization } & 6\end{array}$

Chapter 2. LITERATURE REVIEW --------------------------------- 7

2.1 Non-Destructive Test 7

2.2 NDT Comparison And Feasibility Study 11

$\begin{array}{ll}2.3 & \text { Bending Test In Brittle Materials } \\ & 12\end{array}$ 
3.1 Vibration Analysis

3.2 Four-Point Bending Analysis

4.1 Instrumentation 20

4.2 Test Specimens $\quad 21$

4.3 Testing Setups And Procedures 22

4.4 Experiments 23

4.4.1 Schumacher Dia Schumalith Filters 23

$4.5 \quad$ Experimental Results 24

4.6 Vibration Test On A Broken Schumacher Filter 25

$\begin{array}{lll}4.7 & \text { Weights of Filters } & 27\end{array}$

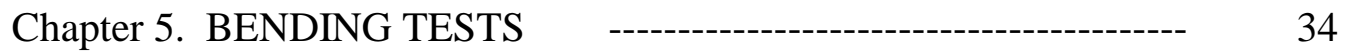

5.1 Introduction 34

5.2 Four-Point Bending Analysis 36

$\begin{array}{lll}5.3 & \text { Instrumentation } & 37\end{array}$

$\begin{array}{lll}5.4 & \text { Experimental Procedure } & 38\end{array}$

$\begin{array}{lll}5.5 & \text { Experimental result } & 40\end{array}$

5.6 Comparison Of Vibration And Bending result 42 
Chapter 6. NUMERICAL STUDY

6.1 Introduction 53

6.2 Dynamic FEM Analysis 54

6.2.1 Stiffness Effect $\quad 56$

6.2.2 Effect Of Poisson's Ratio 57

$\begin{array}{lll}6.3 & \text { Comparison } & 57\end{array}$

6.3.1 Comparison Between Experimental and Theoretical Results $\quad 57$

6.3.2 Comparison Between Experimental and FEM Results 59

6.4 Damage Analysis And FEM Analysis On A Broken Filter 62

$\begin{array}{lll}6.5 & \text { Static FEM Analysis } & 65\end{array}$

Chapter 7. DISCUSSIONS - 66

Chapter 8. CONCLUSIONS AND RECOMMENDATIONS -------- 78

$\begin{array}{lll}8.1 & \text { Conclusions } & 78\end{array}$

8.2 Recommendation for future Research 79

$\begin{array}{ll}\text { REFERENCES } & 81\end{array}$

$\begin{array}{ll}\text { APPENDIX A } & 83\end{array}$ 


\section{LIST OF TABLES}

4.1 Specimen Numbers of Tested Filters 23

4.2 Frequencies Averaged for all Impact and Sensor Locations for Different 27 Schumacher Specimens

4.3 Frequency Comparison of Schumacher A-Group and B-Group and New Filters

4.4 Frequencies and FRF at Different Mode of Repaired A-4 Schumacher Filter 28

4.5 Frequencies of A-4 Schumacher Filter Before Broken and After Repaired 29

4.6 Weights of Schumacher A-Group and B-Group Filter 29

5.1 Weights and Material Properties Tested Filters 39

5.2 Loads and Deflection of Schumacher A-29 Filter 44

5.3 Loads and Deflection of Schumacher A-23 Filter 44

5.4 Loads and Deflection of Schumacher B-5 Filter 45

5.5 Loads and Deflection of Schumacher B-16 Filter 45

5.6 Loads and Deflection of Schumacher B-27 Filter 46

5.7 Loads and Deflection of Schumacher New Filter 46

5.8 Loads and Deflection of Refractron Filter 47

5.9 Stiffness of Tested Filters for Four-Point Bending Tests 47

5.10 Young's Moduli of Schumacher and Refractron Filters 48

5.11 Deflection and comparison among Experimental, Theoretical and FEM Results

6.1 Frequencies and Percentage Difference of Experimental and Bernoulli-Euler Results

6.2 Comparison of Experimental and FEM Frequencies for Refractron Filter 
6.3 Comparison of Experimental and FEM Frequencies for Schumacher A-Group 60 and B-groups filters

7.1 Frequencies and Percentage Difference Between FEM and Bernoulli-Euler 68 Result for A-Group and B-Group Schumacher Filters

7.2 Frequencies Using Different Methods for A-Group and B-group Schumacher 69 Filters

7.3 Frequency comparison of A-4 Repaired Schumacher Filter 


\section{LIST OF FIGURES}

$4.1 \quad$ Vertical Setup $\quad 22$

4.2 Typical Input Waveform in the Time-Domain 30

4.3 Typical Output Waveform in the Time-Domain 30

4.4 Typical Frequency Response Function (FRF) 31

4.5 Frequency Comparison of A-Group, B- Group and New Schumacher Filters 31

4.6 Impact Location on the Filter 32

4.7 The First Mode Shape of Schumacher A-4 Filter Before and After $\begin{array}{ll}\text { Repaired } & 33\end{array}$

4.8 The Third Mode Shape of Schumacher A-4 Filter Before and After Repaired

5.1 Four-Point Bending Experimental Setup $\quad 38$

5.2 Schaevitz LVDT Calibration Chart 40

5.3 Load and Deflection of Schumacher A-29 Filter 49

5.4 Load and Deflection of Schumacher A-23 Filter 49

5.5 Load and Deflection of Schumacher B-5 Filter 50

5.6 Load and Deflection of Schumacher B-16 Filter 50

5.7 Load and Deflection of Schumacher B-27 Filter 51

5.8 Load and Deflection of Schumacher New Filter 51

5.9 Load and Deflection of Refractron Filter 52

5.10 Distribution of Stiffness for Bending Tests 52 
6.1 Three Dimensional Ceramic Filter FEM Model 55

6.2 Comparison of experimental and FEM Frequency for A-Group Schumacher Filter

6.3 Comparison of experimental and FEM Frequency for B-Group Schumacher Filter

6.4 FEM Model of Repaired A-4 Schumacher Filter

6.5 The Eighth Vibration Mode for A-4 Repaired Schumacher Filter 64

7.1 FEM Model of A-4 Repaired Schumacher Filter With Epoxy Glue 71

7.2 FEM Model of Four-Point Bending with Two Spring Supports 76

7.3 Degradation of Tested filters from Bending and vibration tests 77 APPENDIX A

A.1 Picture of Schumacher Specimens \# A-3, A-4, A-20

A.2 Picture of Schumacher Specimens \# A-23, A-26, A-29 83

A.3 Picture of Schumacher Specimens \# A-19, B-16, B-19 84

A.4 Picture of Schumacher Specimens \# B-5, B-7, B-27 84

A.5 Picture of Four-Point Bending Test Setup 85

A.6 Picture of Repaired A-4 Schumacher Filter 85 


\section{CHAPTER 1}

\section{INTRODUCTION}

\subsection{Introduction}

Ceramic candle filters play a key role in the advanced coal-based gas turbine systems. They protect the heat exchanger and gas turbine components from getting clogged and also prevent erosion due to particle impaction. They are capable of withstanding significantly high temperature and pressure over a greater period of time. In order to understand the performance characteristics of ceramic candle filters, they were implemented and operated in four different test facilities (Lippert et al., 1993). The results indicated that strength degradation due to thermal transient events, excessive ash accumulation, bridging and pulse cleaning contributed to the damage of these filters.

Schumacher, manufacturer of ceramic candle filters, has conducted tests on Schumacher filters using various methods. In the non-destructive method, they use visual control, sound check, dimensional check, weight, differential pressure, TOF (time of flight), bubble test and 4-point bending proof test. In the destructive test method, they conducted O-ring compression test, C-ring compression test, bursting pressure and 4-point bending test. Westinghouse Electric Corporation, Science and Technology Center, has tested ceramic candle filters at two test facilities. Test facility was at the Ahlstrom $10 \mathrm{MW}$ (thermal) Circulating Fluidized Bed Combustion (CFBC) located in Karhula, Finland (Lippert et al., 1993). Westinghouse Advanced Particulate Filtration (W-APF) system was used for these tests. The other was the Pressurized Fluidized Bed Combustion (PFBC) test facility at the American Electric Power (AEP) demonstration plant in Brilliant, Ohio. The 
used candle filters showed micro-crack formations in the alumina/mullite filter matrix. These cracks were suspected to occur within the binder phase and through the silicon carbide grains in the clay bonded silicon carbide candle filters. Studies by the Westinghouse researchers also showed that creep crack growth and the formation of ash bridges within the candle arrays generally lead to bowing and tilting of clay bonded SiC candle filters. In the case of SiC candle filters the crack initiation has been found to occur at the inner surface of the hollow cylindrical filters (Alvin et al., 1994).

\subsection{Objectives}

The objective of this study is to use the bending method to confirm the results from the vibration technique for non-destructive evaluation for ceramic candle filter inspection. This nondestructive evaluation technique was to be used during power plant annual maintenance shutdowns. After the feasibility evaluation of three non-destructive testing techniques, it is concluded that the low frequency mode acoustic characterization is the most viable technique.

To study the degradation of ceramic candle filter and damage location, a new Schumacher filter and a repaired Schumacher filter were examined by using the nondestructive dynamic evaluation. These results were used to compare to the previous vibration results by Chen and Parthasarathy (1996). 


\subsection{Scope}

This study tests the capability of the four-point bending method by employing the technique to examine ceramic candle filters, and also to verify the technique for nondestructive evaluation. A new Schumacher filter is examined by using nondestructive evaluation. Its results will be used to study the degradation of ceramic candle filters due to different operating hours.

\subsubsection{Literature Review}

A literature search was conducted on Wilson Index, Mountainlynx and Compendex databases. The search was focused on non-destructive evaluation (NDE) and bending technique for High Temperature High Pressure (HTHP) ceramic filters. The literature collection included reports, journals, conference proceedings and theses. Several publications regarding using NDE on ceramic materials were located in the annual QNDE (Qualitative Non-Destructive Evaluation) conferences and other similar conferences.

\subsubsection{Non-Destructive Evaluation Studies}

Thirteen filter specimens were received at WVU for nondestructive evaluation, including 12 Schumacher Dia Schumalith F40 ceramic filters and 1 Refractron ceramic filters. Based on the age of the filters, three general classifications were made: virgin filter (Refractron filter), 460 hour filters (Schumacher B specimens) and 1705 hour filters (Schumacher A specimens). Dynamic characterization using impact response technique and 
modal analysis have been conducted on these specimens. The evaluation of experimental results is based on two vibration parameters: frequency shifts and mode shapes. Time domain vibration waveforms have been obtained for each specimen using an accelerometer and an oscilloscope. The accelerometer was fixed at a specific location on the filter, and impacts were given using an impact hammer. In order to construct vibration mode shapes, several designated locations on the filter were impacted. The time domain data were then converted to frequency domain to estimate the Frequency Response Functions (FRFs). A total of 8 modal vibration frequencies were estimated for each specimen. Static characterizations using bending test have also been conducted on seven filters. Deflections have been obtained for each filter using LVDT.

\subsubsection{Damage Analysis}

FEM analyses have been conducted to study the effect of distributed damages on the vibration parameters to account for degradation in the filters due to extensive heating cycles and long usage. Different FE models were also constructed to simulate the behavior of the damaged filters to assume a limited zonal damage with degraded material strength.

A Schumacher filter, specimen number $2152 / 355 \mathrm{C}$, was broken into two pieces during the bending test, one piece was $80 \mathrm{~cm}$ (31.5 in.) and the other was $71 \mathrm{~cm}(28$ in.). This filter, categorized as A-4 filter, was used for the evaluation of damage location. These two pieces of the A-4 filter were glued together by using epoxy glue. A model of the damaged A-group Schumacher filter was constructed for the FEM analysis. 


\subsubsection{Bending Test and Analysis}

Bending tests were performed to estimate the Young's modulus from the experimental load-deflection curve. That value of Young's modulus was then compared to the predicted values from vibration analysis. Four-point bending tests were conducted on seven intact filters. These filters were five used Schumacher filters, one new Schumacher filter and one new Refractron filter. Finite element model was developed for these filters. Linear static stress analysis was performed.

\subsubsection{Numerical Studies}

A number of Finite Element Method (FEM) analyses have been conducted to evaluate and collaborate the experimental results. The modal and static analyses were performed. Some parametric studies were also conducted to determine the influences of various material properties on the results. These properties include Young's Modulus and Poisson's ratio. A finite element model has been built for each type of filters.

\subsection{Organization}

The content of this thesis includes 8 chapters. Literature review is described in chapter

2. Chapter 3 describes theoretical study of vibration and bending tests. The experiment, 
specimens, instrumentation, procedure and result of vibration test and four-point bending test are described in chapter 4 and chapter 5 respectively. Chapter 6 includes dynamic and static finite element analysis on the intact filters, and dynamic finite element analysis on a repaired filter, which was broken into two pieces. Chapter 7 presents a discussion about vibration and bending tests. The last chapter summarizes the result of vibration and bending tests and recommendation for future developments. 


\section{CHAPTER 2}

\section{LITERATURE REVIEW}

\subsection{Non-Destructive Test}

Non-destructive testing is to determine the exiting state or quality of materials without impairing its future use. The method of non-destructive testing has been widely used for inspection. The essential component of any non-destructive testing system is:

- Application of a testing or inspection medium

- Detection of damage by suitable detector

- Conversion of this change into a form suitable for interpretation

- Interpretation of information obtained

Ceramic candle filter element, which can withstand the hot gas cleanup environment, are required for use in both Integrated Gasification Combined Cycle (IGCC) and Pressurized Fluidized Bed Combustion (PFBC) systems. To meet the demands of these systems, filter elements must sustain the thermal stress of normal operation without catastrophic failure. They must also survive the mechanical loads associated with handling and assembly, normal operation and process upsets. Schumacher and Pall manufactured SiC particle candle filters with a different binder, Schumacher FT20 and Pall 326, intended to decrease the creep rate. Southern Research Institute tested these filters by measuring axial 
tensile stress, hoop tensile stress, tensile creep, thermal expansion, and thermal conductivity. These filters were tested as received, after $540 \mathrm{hr}$. of PFBC service, and after $1160 \mathrm{hr}$. of PFBC service. Tests performed after PFBC service has provide an indication that these materials possess the ability to survive long-term operation in a hot gas, high pressure dirty environment. Test results on as-received Schumacher FT20 and Pall 326 indicate that the creep rate has indeed been decreased by about an order of magnitude. The temperature where creep begins to occur has been increased by $100^{\circ} \mathrm{F}$ to $200^{\circ} \mathrm{F}$. The improved creep resistance comes at the price of reduced room temperature strength. The FT20 and 326 materials have nearly the same strength as the F40 and $442 \mathrm{~T}$ materials in the operating temperature range. Testing of FT20 and 326 materials after PFBC service indicated that property degradation occurred in the first $540 \mathrm{hr}$. of service. Testing of these materials after $1160 \mathrm{hr}$. of operation at the PFBC was to show whether degradation continued after the initial $540 \mathrm{hr}$. or stopped. (J.D. Spain and H.S. Starrett, 1997)

Microstructure examinations Schumacher F40 and Pall 326 have been used to provide material models which explain the behavior of these materials. These material models have shown that the behavior of the candle filters is controlled by the ceramic binder. Microstructure examination of material after exposure in the PFBC and IGCC environments may allow the mechanism of property degradation to be determined.

Westinghouse Electric Corporation has conducted tests on Coors alumina/mullite, Pall Vitropore 442T, and Schumacher Dia Schumalith F40 clay bonded silicon carbide ceramic candle filters. They used the candle filters from Karhula CFBC and Tidd PFBC plants to test the durability of the ceramic candle filters. They found that a loss in bulk material strength of 
clay bonded silicon carbide filters occurred after being used in the High Temperature High Pressure (HTHP) environment. A greater loss of bulk material strength was reported to appeared and occur along the inner diameter surface of the filters. It was reported that bowing and/or tilting of the clay bonded silicon carbide candles have been frequently encountered when ash bridges formed within the candle arrays (M. A. Alvin et al., 1994).

Spain and Starrett of Southern Research Institute in their final report to the U.S. Department of Energy have put forward their test results of "Physical, Mechanical, and Thermal properties of Schumacher and Refractron SiC filter material" (1994). They used non-destructive testing technique to find out the filter material properties like bulk density, sonic velocity, profilometry, and opening porosity. They conducted axial tension, axial compression, and tensile tests of rings at room temperature to determine their mechanical properties. For the Schumacher filters they performed the tests on virgin filters, and on those retrieved from Tidd Pressurized Fluidized Bed Combustion (PFBC) demonstration plant as well as on heat soaked filters. Their results on virgin candle filter showed that the filters had an average bulk density of $1.885 \mathrm{gr} / \mathrm{cm}^{3}$ and that their ultimate tensile strength increased with temperature from $70^{\circ} \mathrm{F}$ to $1500^{\circ} \mathrm{F}$ and then decreased with temperature thereafter. The Elastic Modulus decreased from $5.9 \times 10^{6} \mathrm{psi}$ at $70^{\circ} \mathrm{F}$ to $3.0 \times 10^{6} \mathrm{psi}$ at $1600^{\circ} \mathrm{F}$. Flexural test results indicated that the softening of the glass binder occurred at around $1400^{\circ} \mathrm{F}$.

For the tests performed on the filters retrieved from Tidd PFBC demonstration plant they obtained the average bulk density value as $1.881 \mathrm{gr} / \mathrm{cm}^{3}$. They found that the average ultimate tensile strength increased from $410 \mathrm{psi}$ at room temperature to $760 \mathrm{psi}$ at $1500^{\circ} \mathrm{F}$. Ultimate strength of the used material was found to be around $37 \%$ of the ultimate strength of virgin material at room temperature and around $56 \%$ of ultimate strength of virgin material at 
$1500^{\circ} \mathrm{F}$. Elastic Modulus decreased from $4.2 \times 10^{6} \mathrm{psi}$ at $70^{\circ} \mathrm{F}$ to $2.0 \times 10^{6} \mathrm{psi}$ at $1500^{\circ} \mathrm{F}$. Flexural test results indicated that the softening of the glass binder occurred at around $1425^{\circ} \mathrm{F}$.

For the heat soaked test the candle filters were subjected to 10 hours heating at $1500^{\circ} \mathrm{F}$ or $1700^{\circ} \mathrm{F}$. These results indicated that temperature exposure alone caused at least some of the strength reduction in the filter retrieved from Tidd. It was concluded that the additional damage was due to chemical attack. A similar procedure was also conducted on the virgin Refractron filter and used Refractron filter retrieved from Karhula hot gas cleanup plant. This test was conducted by SRI researchers.

Virgin Refractron filter material showed a bulk density of $1.77 \mathrm{gr} / \mathrm{cm}^{3}$. The ultimate strength was changed from $2000 \mathrm{psi}$ at $70^{\circ} \mathrm{F}$ to $1430 \mathrm{psi}$ at $1600^{\circ} \mathrm{F}$. In this temperature range the Elastic Modulus decreased from $6.0 \times 10^{6}$ psi to $2.6 \times 10^{6}$ psi. For the tests performed on the filters retrieved from Karhula the average bulk density was found to be $1.85 \mathrm{gr} / \mathrm{cm}^{3}$. The average axial ultimate tensile strength varied from $1180 \mathrm{psi}$ at $70^{\circ} \mathrm{F}$ to $1210 \mathrm{psi}$ at $1600^{\circ} \mathrm{F}$. The Elastic Modulus varied from $6.7 \times 10^{6}$ psi to $2.3 \times 10^{6}$ psi in that temperature ranges. For the tests performed on heat soaked Refractron filters no change in density was observed after temperature exposure at $1700^{\circ} \mathrm{F}$. The strength reduction was observed to be the same for heat soak duration from 3 hours to 216 hours from which it was concluded that strength reduction occurred within the first three hours of exposure to temperature. Chemical reduction of the strength was concluded on comparison with the test results on specimens retrieved from Karhula. 
Stringer and Leitch (1992) conducted tests to evaluate the ceramic candle filter performance at the Grimethorpe (UK) Pressurized Fluidized Bed Combuster. The filters they tested were Schumacher Dia Schumalith filters, which were 1.5 meter long, of 60-mm outer diameter and a wall thickness of $15 \mathrm{~mm}$. The Schumacher filters consist of an inner support made from silicon carbide granules with a thin outer layer composed of fine alumina fibers and silicon carbide grains. A clay binder is used as the bonding agent in each case. Their study concentrated on optimizing the pulse-cleaning air usage and the pulse-cleaning cycle and the candle strength degradation mechanisms. They concluded that the dislodging of the dust cake occurs due to a shock wave that propagates through the porous medium during pulse cleaning. They suggest that it is advantageous to leave a thin layer of dust remaining on the candle because the filter/dust cake interface is then essentially stable, and further impregnation of the filter by dust will not occur. They observed that the weakening of the filters was generally throughout the length of the filters although the strength of the material at the internal diameter was less than that at the outer surface. Also they observed a good correlation between C-ring compression strength and the ultrasonic time of flight. This reinforced the above observation.

\subsection{NDT Comparison And Feasibility Study}

Ultrasonic testing usually involves high frequency $(>100 \mathrm{kHz})$ waves that are induced into the structure. Where impact vibration involves low frequency $(<20 \mathrm{kHz})$ as mechanical vibrations. Some resources have been conducted using self-emitting stress waves called acoustic emissions, which occurs when material experiences molecular deformations or 
fracture. The acoustic emission study also involves high frequency level of acoustics. Acoustic emissions are defined as " the class of phenomena whereby transient elastic waves are generated by the rapid release of energy from the localized sources within a material" (Mindness, 1991). The method of acoustic emission is to demonstrate capabilities for monitoring structural integrity and characterizing material behavior. Acoustic emission examination is non-directional and occurs in most materials which are caused by irreversible changes, such as crack initiation and propagation, dislocation movement and so on. Most acoustic emission sources appear to function as point source emitters that radiate energy in spherical waves. A sensor located anywhere in the vicinity of an acoustic emission source can detect the resulting acoustic emission. A feasibility study has been conducted to determine the most viable technique for ceramic filter testing, these evaluations are based on factors such as applicability of testing procedures, cost and accessibility, etc. When high frequency testing like ultrasonic pulsars and sensors are used, due to the porous nature of the candle filters, there is a high attenuation of the waves thus not yielding any useful results. On the other hand, using low frequency testing such as impact dynamic testing, the attenuation is less and so can be used effectively for porous material like the ceramic candle filter. Also, using the low frequency testing, the overall structural integrity of the structure can be evaluated.

\subsection{Bending Test of Brittle Materials}

The bending method is the other way to inspect material properties. In this research, it 
is applied to confirm the dynamic response analysis. The amount of deflection a beam or tube may undergo when it is subjected to a load can be used to analyze the modulus of elasticity of a material. The analytical methods for obtaining deflections include the integration method, the use of discontinuity functions, the method of superposition and the area moment method. These methods need constants of integration by evaluating boundary conditions, which include the functions for shear, moment, slop or displacement at a particular point on the beam or tube. In this research, four-point bending tests were conducting on the ceramic candle filters. The center deflections were measured and used to reflect the material strength of filters.

Schumacher, a manufacturer of ceramic candle filters, has used four-point bending test and O-ring and C-ring tests to examine the ceramic filter elements. The four-point bending test is to measure the elements, which has a high strength. There are at least 10-filter elements for determination of the four-point bending strength. During the test, each filter will have 8 rotations for loading. The advantages of four-point bending test are (1) No influence of sample (2) Element is nearly completely tested. But there is a disadvantage that head and bottom part not tested. The four-point bending test, conducted in Schumacher Company, can determine the reliability and the lifetime of the ceramic candle filter and discover defective filter elements. O-ring and C-ring are compressing test on the filter. The change of tensile stresses and compression stresses can be used to determine the Young's Modulus. (PSDF, 1998)

Investigation of property variations in thermally sprayed materials by Vickers 
indentation tests, four-point bending test with in-situ acoustic emission monitoring is performed. In order to study the variations within the thermal spray coatings, two major experimental techniques; i.e., indentation and acoustic emission (AE), were used. The

experimental results were then analyzed statistically. The highly variable nature of thermal spray coatings was studied by an indentation technique in a microhardness range. Three different loads were used to assess the variability with respect to the test volume. The microhardness variations with respect to different heat-treated conditions was also studied. In addition, the reliability of the microhardness test results will be assessed by a Monte Carlo method. The variation throughout the coating was determined by the microhardness distribution at various locations of interest. (Chung-Kwei Lin, 1995).

A new technique, indentation-scratch, is developed to generate high quality, cleavage surface precracks in brittle materials. An indentation roller equipped with weight attachment rolls across the specimen surfaces to generate precracks in four-point bending specimens (Y.B.Xin and K.J. Hsia, 1995). The residual stresses induced during indentation are effectively eliminated by mechanically grinding away the inelastically deformed surface layer. The intrinsic fracture toughness measured by the present method is in good agreement with the data in literature. The dislocation nucleation condition, associated with the onset of the increase of subsequent room temperature fracture toughness following high temperature prestressing at $500^{\circ} \mathrm{C}$, is determined.

Ogawa and Sugiyama (1996) developed a new technique for the three-point impactbending test in the split Hopkinson pressures bar method. The new method was experimentally confirmed and was applied to characterize the impact strength of four kinds of 
advanced brittle materials, fiber reinforced plastics (GFRP and CFRP), fiber reinforced ceramics, and fiber bonded ceramic composite. Smooth transmitted stress waves were measured without any artificial filtering procedure only by applying appropriately ramped incident stress waves. The

dynamic load-deflection curves were obtained to evaluate the strength through the usual stress wave analysis, and the rate effect on the tensile and the shear strength of the materials was clarified. Specimen geometry and elastic aeolotropy were discussed in connection with deformation behavior and fracture morphology.

Three point impact bending tests on fiber-reinforced ceramics were carried out using a split-Hopkinson pressure bar method (Fumiko Sugiyama and Kinya Ogawa, 1996). Ramped incident waves were produced by plastic deformation of zinc and were applied to the specimens. Smooth transmitted stress waves without high-frequency fluctuation were obtained to evaluate dynamic stress-strain relations precisely. The bending modes in the impact tests were found to be almost the same as the static ones and dynamic strength can be measured exactly. Numerical analysis using finite-element method showed that analytical results agree with experimental results very well. 


\section{CHAPTER 3}

\section{THEORETICAL STUDY}

\subsection{Vibration Analysis}

The Bernoulli-Euler beam theory was used to simplify the candle filter structure. The basic equation is as follows:

$$
E I \frac{d^{4} y}{d x^{4}}+m \frac{d^{2} y}{d t^{2}}=p(x, t)
$$

On solving this equation for the free-free beam case the frequency equation obtained is

$$
\cos \left(a_{n} L\right) * \cosh \left(a_{n} L\right)-1=0
$$

which has to be solved for the different values of ' $a$ '. The frequency of vibration of the structure in the various modes can be calculated using the equation:

$$
\omega_{n}=C_{n} \sqrt{\frac{E I}{m L^{4}}}
$$


In the above equations $m$ is the mass per unit length of the beam, $\mathrm{p}(\mathrm{x}, \mathrm{t})$ is the impact load per unit length on the beam, $E$ is the Modulus of Elasticity of the material of the structure, $I$ is the moment of inertia of the structure about the cross-section, $L$ is the total length of the beam, $C_{n}$ is equal to the square of $\left(a_{n} L\right)$. Knowing the value of the Young's Modulus, Moment of Inertia, mass per unit length, length of the beam and $a_{n}$, the frequency of vibration of the structure at $\mathrm{n}$ modes can be determined.

Also the mode shape can be calculated using the following formula

$$
\begin{aligned}
& \phi_{n}(x)=\cosh \left(a_{n} x\right)+\cos \left(a_{n} x\right)-\sigma_{n}\left(\sinh \left(a_{n} x\right)+\sin \left(a_{n} x\right)\right) \\
& \text { where, } \quad \sigma_{n}=\frac{\cosh \left(a_{n}\right.}{\sinh \left(a_{n}\right.} \frac{L)-\cos \left(a_{n}\right.}{L)-\sin \left(a_{n} L\right)}
\end{aligned}
$$

All the above parameters are constant for a given specimen but only the value of $a_{n}$ changes giving the frequencies in various modes.

The frequency values for Schumacher A and B groups filter were calculated using the Equation (3). Using the measured dimensions of outer diameter equals to $60 \mathrm{~mm}$ (2.362 in.) and the inner diameter equals to $30 \mathrm{~mm}$ (1.181 in.), the moment of inertia was calculated. The average weight of all A-group specimens and all B-group specimens was calculated from the measured individual weights and was divided by the length (equal to 59.625 inch) to get the respective weight/mass per unit length values for the A and B group filters. The weight densities calculated for the Schumacher specimens are nominal weight densities, obtained from their measured weights and the measured dimensions. 


\subsection{Four-Point Bending Analysis}

In the beam bending experiment, the deflection curve depends inversely on the modulus of elasticity (E), also depends inversely on the centroidal moment of inertia of the beam's cross section. The way the deflection depends on the applied load, and on the manner in which the beam is supported. The four point bending technique will be used to analyze the material properties, the sketch of experimental set-up is shown in figure 5.1. The equation of four-point bending is shown as follow

$$
\mathrm{E}(\text { Young's Modulus })=\frac{\mathrm{Pa}}{48 \Delta \max \mathrm{I}}\left(31^{2}-4 \mathrm{a}^{2}\right)
$$

In the formula, $\mathrm{P}$ represents the total load (lb.) applied on the filter, 1 is the distance between bottom supports (52"), a is the distance between bottom support and top support (19"), $\Delta$ max. represents the maximum deflection at the center (in.). The moment of inertia is calculated by the following formula:

$$
\mathrm{I}=\frac{\pi^{*}\left(\mathrm{D}_{\mathrm{o}}{ }^{4}-\mathrm{D}_{\mathrm{i}}{ }^{4}\right)}{64}
$$


$\mathrm{D}_{\mathrm{o}}$ is the outer diameter, and $\mathrm{D}_{\mathrm{i}}$ is inner diameter. The Schumacher filter has outer diameter 2.362 inches $(60 \mathrm{~mm})$ and inner diameter 1.181 inches $(30 \mathrm{~mm})$, its moment of inertia equals $1.433 \mathrm{in}^{4}$. The Refractron filter has outer diameter 2.362 inches $(60 \mathrm{~mm})$ and inner diameter 1.575 inches $(40 \mathrm{~mm})$, its moment of inertia equals to $1.226 \mathrm{in}^{4}$. The Young's Moduli will be calculated by using the above geometric properties and deflections from experiments. 


\section{CHAPTER 4}

\section{VIBRATION TEST}

\subsection{Instrumentation}

The impact vibration testing instruments used for doing the experiments are:

1. A PCB impact hammer

The impact hammer is fitted with a force transducer and has a steel cap. It has a frequency range up to $8 \mathrm{kHz}$ and its sensitivity is $10 \mathrm{mV} / \mathrm{lb}$.

2. An Endevco accelerometer

The sensitivity of the accelerometer is $4.65 \mathrm{mV} / \mathrm{g}$. It has a good accuracy in the frequency range of $50 \mathrm{~Hz}-1000 \mathrm{~Hz}(0 \%$ standard deviation) and sufficiently good accuracy in measuring the frequencies below $50 \mathrm{~Hz}$ and above $1000 \mathrm{~Hz}$ (1-2\% standard deviation).

3. A Nicolet digital oscilloscope

It displays both the input and output signals. Signals can be stored directly into a floppy disk.

Initially, ultrasonic pulsars and sensors were used, and the response of the filter was observed for different locations of the sensors. This did not yield any useful results because of the high damping of the waves caused by the filters at high frequencies owing to the porosity of the filters. Vibration analysis was performed to acquire the vibration signatures of the filters, namely the frequency responses and the various vibration mode shapes. 


\subsection{Test Specimens}

The specimens tested for this study is:

1. One Refractron ceramic (clay bonded $\mathrm{SiC}$ ) candle filter of 59 inches (1.5 m) length. It has an outer diameter of 2.362 inches $(60 \mathrm{~mm})$ and inner diameter of 1.575 inches $(40 \mathrm{~mm})$ with a closed end wall thickness of 0.984 inches $(25 \mathrm{~mm})$. The wall thickness along the length is $0.394-$ inch $(10 \mathrm{~mm})$. All these dimensions were given by Pall Corporation, which supplied the Refractron filter. This filter weighed $4.575 \mathrm{~kg}$ (10.09 lbf). This is a virgin (unused) filter.

2. Twelve Schumacher Dia Schumalith ceramic (clay bonded SiC) candle filters, each of 59.625 inch length. These filters have an outer diameter of 2.362 in $(60 \mathrm{~mm})$ and inner diameter of 1.181 in $(30 \mathrm{~mm})$ with a closed end wall thickness of about 1.417 in $(36 \mathrm{~mm})$. The wall thickness along the length is 0.591 in $(15 \mathrm{~mm})$. All these dimensions were measured in-house. These are used filters. Among these 12 candle filters, 7 of them were used for 1705 hours (A group specimens) and 5 of them were used for 460 hours (B group specimens). Figure A.1, Figure A.2, Figure A.3 and Figure A.4 show the pictures of the 12 Schumacher candle filter specimens. Different filters had different weights in this case. These filters had ash deposits on them. A comparison of uncleanness and cleaned weights is shown in Table 4.6. 


\subsection{Testing Setups and Procedures}

Two types of test setups were used to simulate a Free-Free boundary condition for conducting the experiments.

1. A tripod shaped wooden frame from which the filter was suspended vertically using three strings of equal length (Figure 4.1).

2 A rectangular wooden framework from which the filter was suspended horizontally using two elastic (rubber) strings of equal length. Elastic strings were used to minimize the damping effects.

Oscilloscop

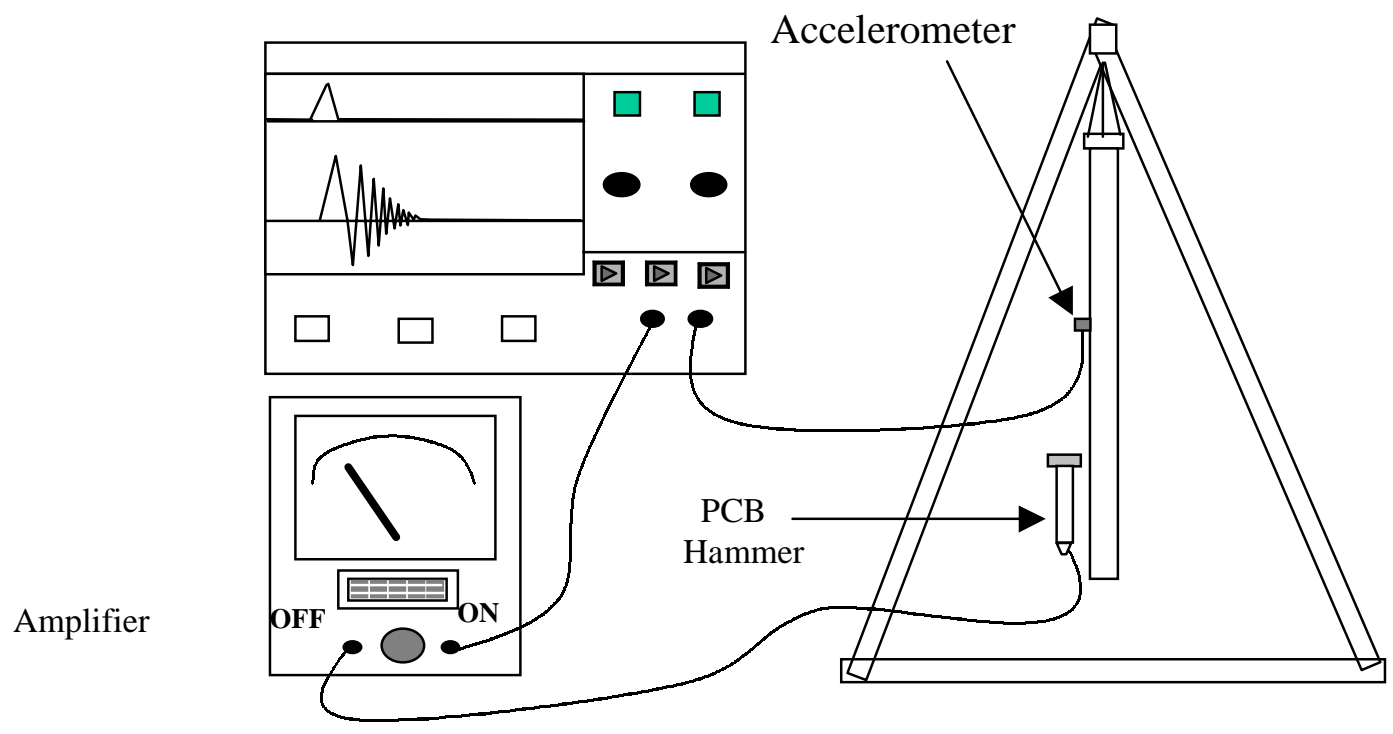

Figure 4.1 Vibration Test Setup 


\subsection{Experiments}

Several tests have been conducted, with different number of impact and sensor locations and test setups. A detailed description of all the tests conducted on the Refractron and Schumacher filters are listed in the Proceeding of Pittsburgh Coal Conference (Chen and Parthasarathy, 1996).

\subsubsection{Schumacher Dia Schumalith Filters}

These filters were provided by Westinghouse Electric Corporation, Science and Technology Center. Twelve filters were tested of which seven were used for 1705 hours and five were used for 460 hours. Each of these filters was of 59.625 inch long. The filter specimen numbers are shown in Table 4.1 .

\begin{tabular}{|c|c|}
\hline $\begin{array}{l}\text { Used for } 460 \text { hrs } \\
\text { B-Group }\end{array}$ & $\begin{array}{l}\text { Used for } 1705 \text { hrs } \\
\text { A-Group }\end{array}$ \\
\hline 1. $343 / 319 B$ B/B-5 & 1. $2155 / 355 \mathrm{C} B / \mathrm{A}-3$ \\
\hline 2. $115 / 317 \mathrm{~B} B / \mathrm{B}-7$ & 2. $2152 / 355 \mathrm{C} B / \mathrm{A}-4$ \\
\hline 3. $089 / 317 \mathrm{~B} B / \mathrm{B}-16$ & 3. $1712 / 348 \mathrm{C} B / \mathrm{A}-19$ \\
\hline 4. $002 / 317 \mathrm{~B} A / B-19$ & 4. $2343 / 364 C \mathrm{~B} / \mathrm{A}-20$ \\
\hline \multirow[t]{3}{*}{ 5. $101 / 317 \mathrm{~B}$ B/B-27 } & 5. $2308 / 364 \mathrm{C} A / A-23$ \\
\hline & 6. $2114 / 355 \mathrm{C} B / \mathrm{A}-26$ \\
\hline & 7. $1715 / 348 \mathrm{C} A / \mathrm{A}-29$ \\
\hline
\end{tabular}

Table 4.1 Specimen Number of 'Tested Filters 


\subsection{Experimental Results}

Fast Fourier Transform (FFT) was used to transform the input signals from time domain to frequency domain. In order to determine the Frequency Response Function (FRF), the output response was divided by the input function. This shows the response of the structure at various frequencies by means of spikes at the respective natural frequencies of the structure. Figure 4.2 shows a typical input waveform in the time domain. In this figure, $\mathrm{X}$ axis represents time in seconds, and Y-axis represents voltage in volts. The duration of a typical impulse input is about 0.5 to 0.6 milliseconds. The frequency range covered by the input loading is a little above $4000 \mathrm{~Hz}$. Similarly, Figure 4.3 shows a typical output acceleration history. Figure 4.4 shows a sample FRF obtained after the output function divided by the input function. In this figure the $\mathrm{X}$-axis represents frequency and the $\mathrm{Y}$-axis represents the amplitude. It can be seen from the figure that there are 8 distinct spikes. The frequency value corresponding to each spike is the natural frequency of vibration of the filter in the respective modes. Only a portion of the FRF output, up to $4000 \mathrm{~Hz}$, is extracted. As the readings are taken for various sensor-impact location combinations, a mode shape can thus be constructed. The sample shown is for a Schumacher group A specimen.

Table 4.2 shows the averaged frequency results for all impact locations and also both sensor locations for each of the group A and group B specimens. The table also shows the average of all group A and group B specimens along with the coefficient of variation (COV) for both groups of specimens in all the modes. The COV is almost constant for both the filter groups. Also the percentage difference in frequency between both the groups remains almost 
the same in all the modes, with an average percentage difference of $5.42 \%$. This is equivalent to a change in the Young's modulus of about $8.16 \%$. It can be seen from the table that in the case of Schumacher filters being used for less number of hours the average frequency value is higher than those used for more number of hours indicating a decrease in the stiffness of the filters through use. Also the COV is less than 3\%, compared with the frequency shift of over $5 \%$ between the two filters. The comparison of A-group, B-group and new Schumacher filters is shown in Figure 4.5. In this figure, the $\mathrm{X}$-axis represents the vibration mode number and the $\mathrm{Y}$-axis represents the frequency of vibration.

It is also noted that the frequency response of the A-23 specimen is almost the same as the B-5 specimen although they are from different groups (Chen and Parthasarathy, 1996). This shows that the frequency difference observed between the two groups of Schumacher specimens is only in an average sense and that caution has to be exercised on the part of the researcher before coming to any final conclusion on the stiffness condition of the filter. In table 4.3 , it can be seen that frequencies of Schumacher filters decrease as the hours of operation increase. No conclusions can be made based on observations from a single

specimen. Such anomalies in results could be due to manufacturing defects, difference in batch number of the filters, or the limitations of the current experimental technique.

\subsection{VIBRATION TEST ON A BROKEN SCHUMACHER FILTER}

A-4 Schumacher filter, specimen number 2152/355C, was broken into two pieces during the bending test, one piece was $80 \mathrm{~cm}$ (31.5 in.) and the other was $71 \mathrm{~cm}(28 \mathrm{in}$.). This 
filter was used for the evaluation of damage location. These two pieces of A-4 filter were glued together by using epoxy glue, which had a strong adhesive strength. The weight density of A-4 Schumacher was $2.018 \mathrm{gm} / \mathrm{cc}\left(0.0729 \mathrm{lb} / \mathrm{in}^{3}\right)$. Its weight was $6.605 \mathrm{~kg}$ and $131.2 \mathrm{~cm}$ (59.625 in.) before broken and $6.61 \mathrm{~kg}$ after glued.

For the vertical test setup, the sensor was placed at the position of $0.55 \mathrm{~L}$ of the filter, and there were eight impact positions were selected which were at $\mathrm{L} / 8, \mathrm{~L} / 4, \mathrm{~L} / 3,5 \mathrm{~L} / 12, \mathrm{~L} / 2$, 2L/3, 3L/4 and 7L/8. Figure 4.6 shows the impact locations on the filter. The damaged location was between $\mathrm{L} / 2$ and $0.55 \mathrm{~L}$. A sampling rate of 20 microsecond was used. This is equivalent to a resolution of $12.5 \mathrm{~Hz}$. Table 4.4 gives frequencies and FRF of repaired A-4 Schumacher filter, which was used to construct mode shapes.

Figures 4.7 and 4.8 give the two different mode shapes of A-4 Schumacher filter before broken and after repaired, which are generated by using the experimental FRF results. In these figures, the $\mathrm{X}$-axis represents the distance along the length of the filter in inches which was measured from the open end, and the Y-axis represents the normalized FRF. The damaged position was between position $5($ at $\mathrm{L} / 2$ ) and position 6 (at $0.55 \mathrm{~L}$ ). As can be seen from these figures, the frequency response function (FRF) of A-4 filter after it was repaired is higher than before it was broken. The frequency obtained after A-4 filter repaired is higher than before it broken, which may be caused by the high strength of the epoxy glue and the length of the filter. The comparison of frequencies of A-4 Schumacher filter before it was broken and after it was repaired is shown in Table 4.5 


\subsection{Weights of Filters}

The Schumacher filters had some ash accumulation on them when received. Hence, they were cleaned using pressurized water before testing. After cleaning they were dried using heater fans to remove the water content from them. After a day of drying they were tested. The filters were weighed before and after cleaning to know the amount of ash deposited on the filters. The uncleaned weights of A-19 and B-16 specimens were not recorded. Also, 3 group B specimens (B-27, B-19, B-7) appeared to be clean when they were received. It can be seen from this figure that A-group filters have higher weights than B-group filters. The volume of the filter was calculated from the measured nominal dimensions as $199.642 \mathrm{in}^{3}$. Also, from the average weights of group $\mathrm{A}=14.275 \mathrm{lb}$. $(6.475 \mathrm{~kg})$ and group $\mathrm{B}=13.788 \mathrm{lb} .(6.254 \mathrm{~kg})$, the average weight densities of group $\mathrm{A}$ and group $\mathrm{B}$ filters was calculated to be $0.0715 \mathrm{lbf} / \mathrm{in}^{3}$ and $0.0691 \mathrm{lbf} / \mathrm{in}^{3}$ respectively. Table 4.6 gives the weights of the tested Schumacher filters.

\begin{tabular}{|c|c|c|c|c|c|}
\hline MODE & $\begin{array}{l}\text { AVRG OF } \\
\text { A-Group }\end{array}$ & $\begin{array}{c}\mathrm{COV} \text { OF } \\
\mathrm{A}\end{array}$ & $\begin{array}{c}\text { AVRG OF } \\
\text { B-Group }\end{array}$ & $\begin{array}{c}\text { COV OF } \\
\text { B }\end{array}$ & $\begin{array}{c}\% \text { DIFF } \\
\text { BETWEEN } \\
\text { A \& B }\end{array}$ \\
\hline 1 & 102.05 & 2.13 & 108.38 & 1.77 & 6.19 \\
\hline 2 & 276.99 & 2.74 & 292.15 & 1.23 & 5.47 \\
\hline 3 & 538.13 & 2.35 & 565.45 & 1.13 & 5.08 \\
\hline 4 & 881.07 & 2.34 & 924.56 & 0.94 & 4.94 \\
\hline 5 & 1286.25 & 2.28 & 1353.19 & 1.04 & 5.20 \\
\hline 6 & 1751.47 & 2.38 & 1843.44 & 0.99 & 5.25 \\
\hline 7 & 2271.12 & 2.44 & 2397.06 & 1.02 & 5.55 \\
\hline 8 & 2830.89 & 2.50 & 2991.25 & 0.83 & 5.66 \\
\hline & & & & AVERAG & 5.42 \\
\hline
\end{tabular}

Table 4.2 Average Frequency of A-Group and B-Group Schumacher Filters (Chen and Parthasarathy, 1996) 


\begin{tabular}{|c|c|c|c|}
\hline Mode & $\begin{array}{l}\text { A-SERIES } \\
\text { (1705 hrs) }\end{array}$ & $\begin{array}{l}\text { B-SERIES } \\
\text { (460 hrs) }\end{array}$ & NEW \\
\hline$\overline{1}$ & 102.05 & 108.38 & 109.86 \\
\hline 2 & 276.99 & 292.15 & 305.18 \\
\hline 3 & 538.13 & 565.45 & 592.04 \\
\hline 4 & 881.07 & 924.56 & 970.46 \\
\hline 5 & 1286.25 & 1353.19 & 1416.02 \\
\hline 6 & 1751.47 & 1834.48 & 1934.82 \\
\hline 7 & 2271.12 & 2397.06 & 2514.65 \\
\hline 8 & 2830.89 & 2991.25 & 3125 \\
\hline
\end{tabular}

Table4.3 Frequency Comparison of Schumacher A-Group, B-Group and New Filters

\begin{tabular}{|c|c|c|c|c|c|c|c|c|c|c|c|c|c|c|c|}
\hline \multicolumn{2}{|c|}{$\bar{L} / \varepsilon$} & \multicolumn{2}{|l|}{$\mathrm{L} / 4$} & \multicolumn{2}{|l|}{$\bar{L} / 3$} & \multicolumn{2}{|c|}{$5 \mathrm{~L} / 12$} & \multicolumn{2}{|l|}{$\mathrm{L} / 2$} & \multicolumn{2}{|c|}{$2 \mathrm{~L} / 3$} & \multicolumn{2}{|l|}{$3 \mathrm{~L} / 4$} & \multicolumn{2}{|c|}{$\overline{7 \mid \_/ 8}$} \\
\hline Freq. & FRF & Freq. & $\mathrm{FRF}$ & Freq. & FRF & Freq. & FRF & Freq. & FRF & Freq. & FRF & Freq. & FRF & Freq. & FRF \\
\hline 106.8 & 0.6 & 106.8 & 0.1 & 103.8 & -0.1 & 103.8 & -0.3 & 106.8 & -0.7 & 103.8 & $\begin{array}{l}-0.3 \\
\end{array}$ & 105.3 & -0.1 & 103.8 & 0.2 \\
\hline 289.9 & 0.1 & 289.9 & 0.7 & 289.9 & 1.0 & 289.9 & 1.1 & 289.9 & -0.1 & 289.9 & -1.0 & 289.9 & -1.0 & 289.9 & 0.0 \\
\hline 566.1 & 1.6 & 566.1 & 2.9 & 566.1 & 2.7 & 566.1 & 0.7 & 566.1 & -3.3 & 566.1 & 0.7 & 566.1 & 2.5 & 566.1 & 1.4 \\
\hline 924.7 & -4.5 & 924.7 & -4.9 & 924.7 & -1.6 & 924.7 & 4.1 & 924.7 & -0.1 & 924.7 & -3.6 & 924.7 & 1.8 & 924.7 & 3.9 \\
\hline 1353.5 & -3.7 & 1353.5 & -2.0 & 1353.5 & 1.6 & 1353.5 & 3.6 & 1353.5 & -3.9 & 1353.5 & 3.6 & 1353.5 & 1.4 & 1353.5 & -3.4 \\
\hline 1847.8 & 7.0 & 1847.8 & -0.2 & 1847.8 & -6.4 & 1847.8 & -1.6 & 1847.8 & -0.4 & 1847.8 & 1.8 & 1847.8 & 6.5 & 1847.8 & -5.9 \\
\hline 2409.4 & 1.2 & 2409.4 & -1.0 & 2409.4 & -1.3 & 2409.4 & 1.2 & 2409.4 & -1.6 & 2409.4 & 1.1 & 2409.4 & -1.5 & 2409.4 & 1.0 \\
\hline 3006.0 & -3.6 & 3006.0 & 6.5 & 3012.1 & 0.8 & 3006.0 & -5.8 & 3006.0 & -0.3 & 3006.0 & 5.4 & 3006.0 & -2.7 & 3006.0 & 2.2 \\
\hline
\end{tabular}

Table 4.4 Frequencies and FRF at Different Mode of Repaired A-4 Schumacher Filter 


\begin{tabular}{|c|c|c|}
\hline Mode & $\begin{array}{c}\text { After Repaired } \\
(\mathrm{Hz})\end{array}$ & $\begin{array}{c}\text { Before Broken } \\
(\mathrm{Hz})\end{array}$ \\
\hline 1 & 105 & 105 \\
2 & 290 & 287 \\
3 & 566 & 556 \\
4 & 925 & 911 \\
5 & 1353 & 1315 \\
6 & 1848 & 1802 \\
7 & 2409 & 2335 \\
8 & 3007 & 2905 \\
\hline
\end{tabular}

Table 4.5 Frequencies of A-4 Schumacher Filter Before Broken and After Repaired

\begin{tabular}{|cccc|}
\hline Filters & $\begin{array}{c}\text { Cleaned } \\
(\mathrm{Kg})\end{array}$ & $\begin{array}{c}\text { Uncleaned } \\
(\mathrm{Kg})\end{array}$ & $\begin{array}{c}\text { Diff. In Weight } \\
(\mathrm{Kg})\end{array}$ \\
\hline A-19 & 6.5 & & \\
A-4 & 6.605 & 6.64 & 0.035 \\
A-3 & 6.475 & 6.645 & 0.17 \\
A-26 & 6.5 & 6.64 & 0.14 \\
A-23 & 6.42 & 6.63 & 0.21 \\
A-20 & 6.375 & 6.53 & 0.155 \\
A-29 & 6.45 & 6.63 & 0.18 \\
\hline Average & 6.475 & 6.619 & 0.148 \\
\hline B-16 & 6.29 & & \\
B-27 & 6.29 & 6.29 & 0 \\
B-19 & 6.3 & 6.3 & 0 \\
B-7 & 6.24 & 6.24 & 0 \\
B-5 & 6.15 & 6.275 & 0.125 \\
\hline Average & 6.254 & 6.28 & 0.022 \\
\hline
\end{tabular}

Table 4.6 Weights of Schumacher A-Group and B-Group Filters (Chen and Parthasarathy, 1996) 


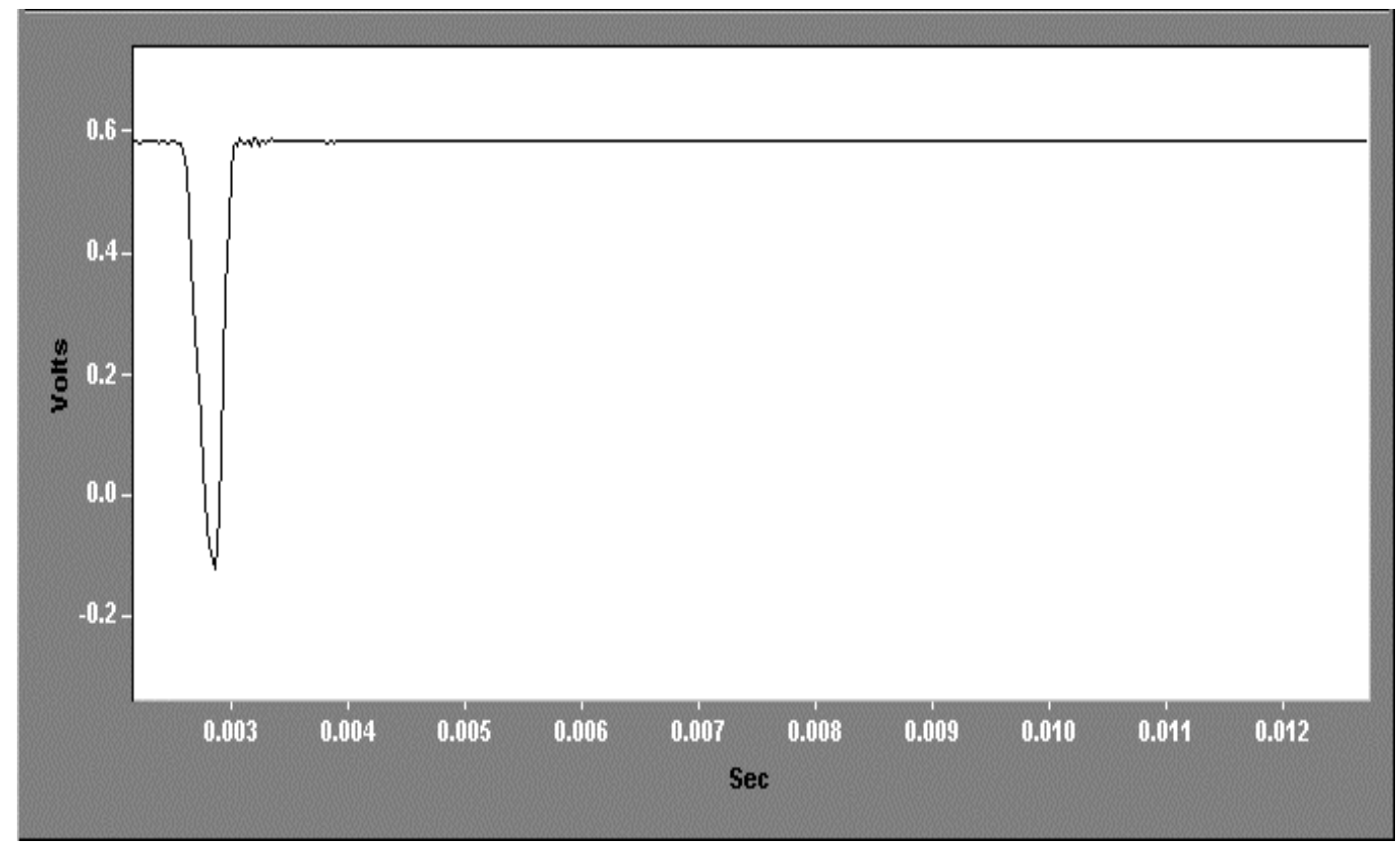

Figure 4.2 Typical Input Waveform in the Time Domain

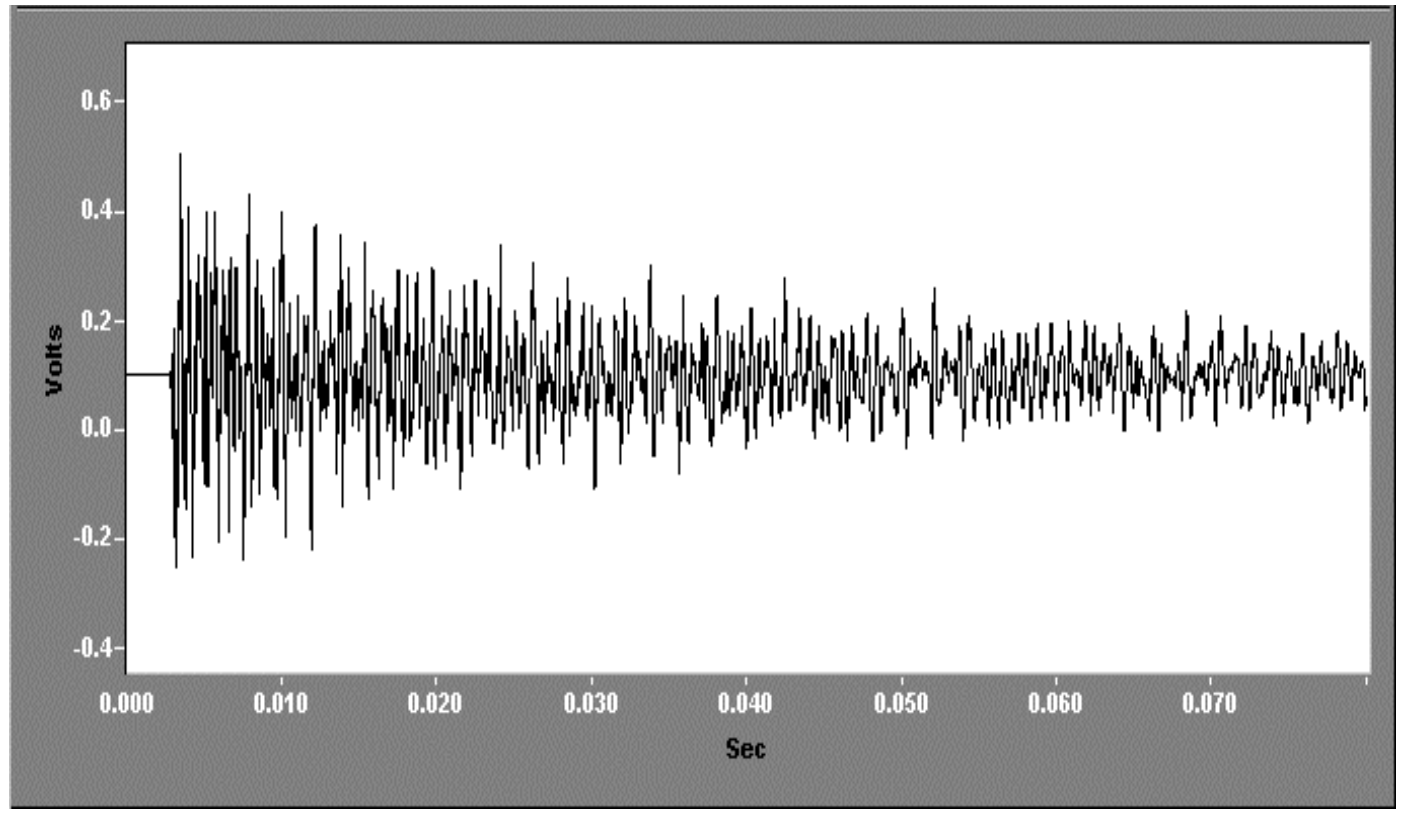

Figure 4.3 Typical Output Waveform in the Time Domain 


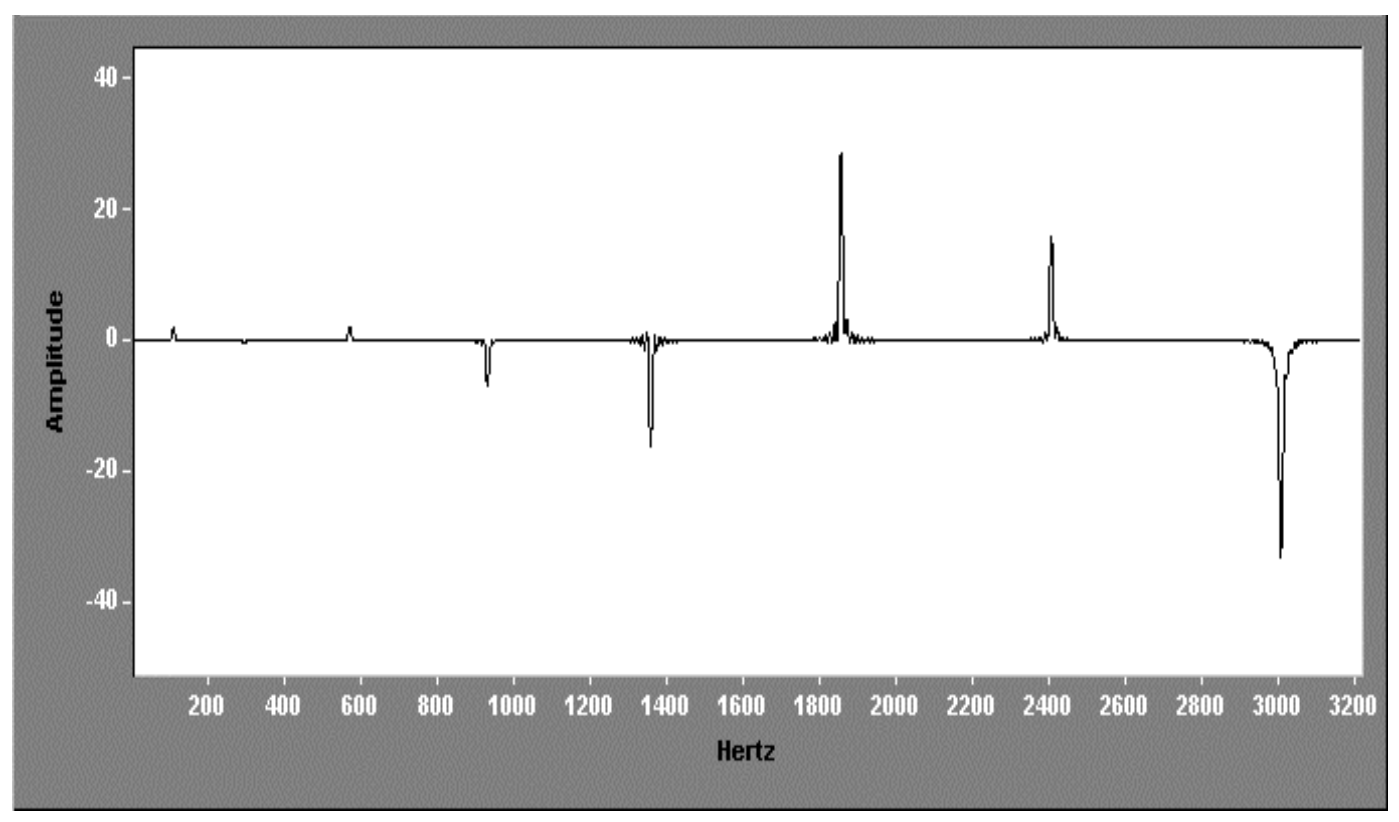

Figure 4.4 Typical Frequency Response Function

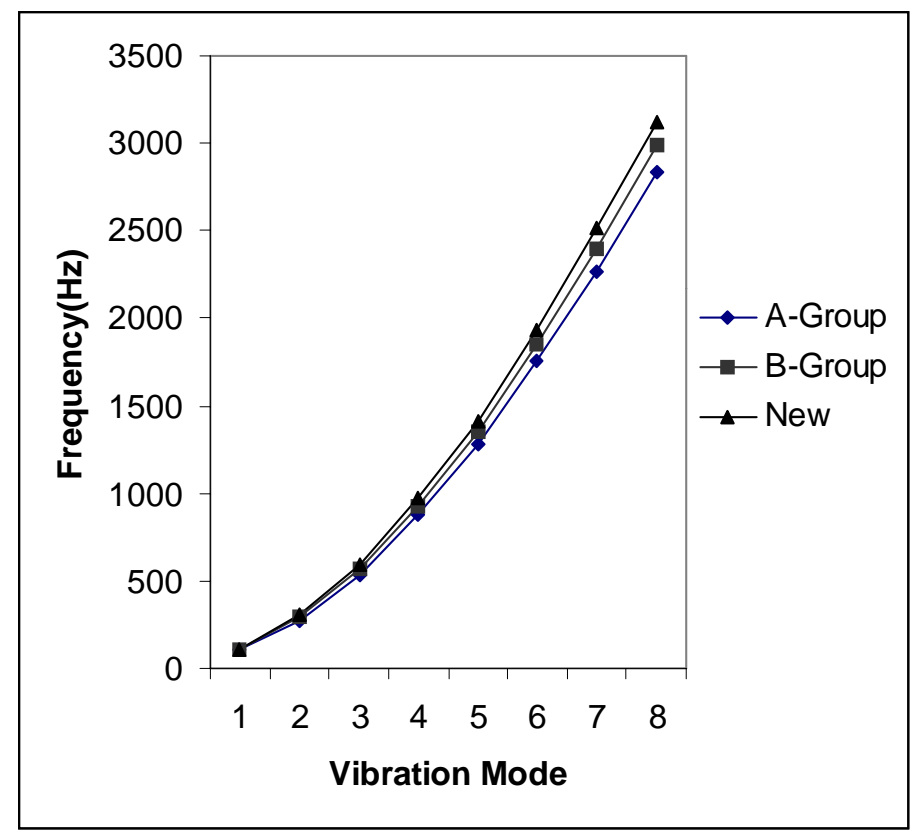

Figure 4.5 Frequency Comparison of A-Group, B-Group and New Schumacher Filters 


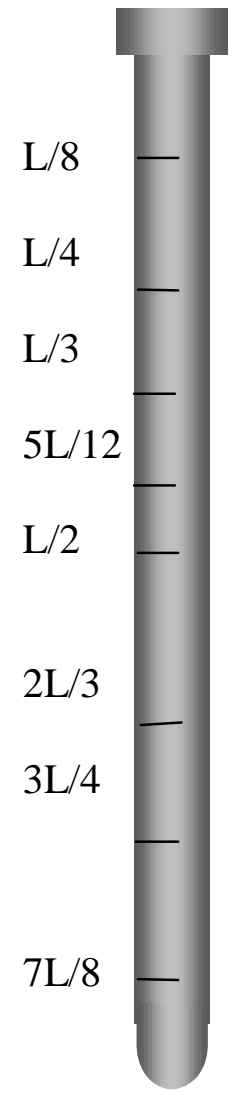

Figure 4.6 Impact Location on the Filter 


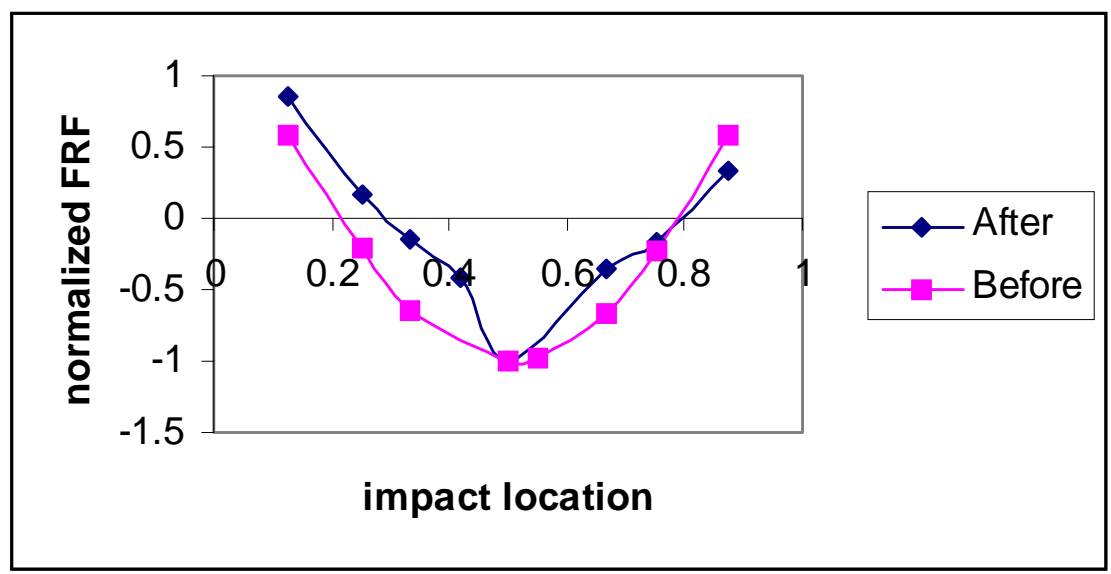

Figure 4.7 The First Mode Shape of A-4 Schumacher Filter Before Broken And After Repaired

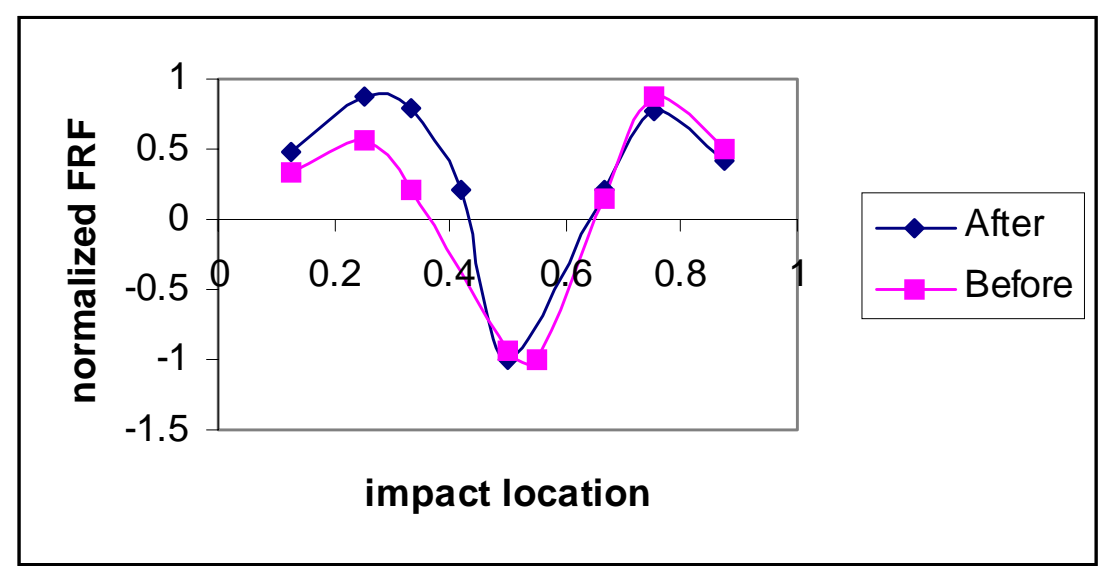

Figure 4.8 The Third Mode Shape of A-4 Schumacher Filter Before Broken And After Repaired 


\section{CHAPTER 5}

\section{BENDING TEST}

\subsection{Introduction}

The result from the previous test, "the established acoustic signature of HTHP ceramic filters at different degradation level", indicated that dynamic response analysis is a feasible means for nondestructive evaluation of ceramic candle filters (Chen and Parthasarathy, 1996). In order to confirm the dynamic response analysis, bending tests were performed to estimate the Young's modulus from the experimental load-deflection curve. The value of Young's modulus was then compared to the predicted values from vibration analysis.

When a load is placed on a beam, the formerly straight horizontal (centroidal) axis of the beam is deformed into a curve. Basically two things will happen when a tube is bent. The outside wall of the tube collapses and thins out, and the inside of the tube compresses and wrinkles (Gere and Timoshenko, 1990). To understand the material property, a mathematical model will be applied to analyze. The goal of mathematical modeling is to represent natural processes by mathematical equations, to analyze the equations, and then to use the model to better understand and predict the natural process. In this module, we are interested in obtaining the deflection of loaded ceramic filters and predicting the Young's moduli by modeling their deflection curves. The shape of the deflection curve will depend on the following several factors: 
- The material properties of the ceramic filters as measured by the modulus of Elasticity.

- The ceramic filter's cross section as measured by its centroidal moment of inertia.

- The load on the filters, described as a function of the position along the beam.

- The way the filter is supported, which is captured by the boundary conditions of the differential equation in our model.

Four- point bending tests were conducted on seven intact filters. There are five used Schumacher filters, one new Schumacher filter and one new Refractron filter. Five used Schumacher filters included two A- group filters, which had been used for 1705 hours, and three B-group filters, which had been used for 460 hours. The following are specimen numbers for each tested filter.

\begin{tabular}{|c|c|}
\hline Filter & Spécimen Number \\
\hline New Refractron & Not available \\
New Schumacher & $506 / 322 \mathrm{~B}$ \\
A-29 Schumacher & $1715 / 348 \mathrm{C}$ \\
A-23 Schumacher & $2308 / 364 \mathrm{C}$ \\
B-5 Schumacher & $343 / 319 \mathrm{~B}$ \\
B-16 Schumacher & $089 / 317 \mathrm{~B}$ \\
B-27 Schumacher & $101 / 317 \mathrm{~B}$ \\
\hline
\end{tabular}




\subsection{Four-Point Bending Analysis}

A thin-walled closed-section tube subjected to bending suffers significant crosssectional distortion; the result has greater flexibility than the predicted result by beam theory. Thicker tubes exhibit a similar departure from beam theory due to inelastic material behavior. The beam bending theory was applied to calculate the results of the bending tests on the candle filters because of its simplicity.

A symmetrical four-point bending test was conducted on the filters. Bending moments were inferred from the load applied on the four-point fixture by the testing machine and the applied load. In the bending test, the deflection in the center of the filters was measured. The load-deflection ( $\mathrm{P}-\Delta$ ) curve was measured up to $200 \mathrm{~N}$ (45.7 lb.). The following is to study the stresses occurred in the cross section of ceramic candle filter when maximum load of 35.7 lb. is applied on the filter. The maximum compression and tensile stresses are $243 \mathrm{psi}$, and the compression stress at point $\mathrm{b}$ and tensile stress at point $\mathrm{c}$ are $121.5 \mathrm{psi}$.

$$
\begin{aligned}
& \mathrm{I}=1.433 \mathrm{in}^{4} \\
& \begin{aligned}
\mathrm{M}= & 17.85 \times 16.5 \\
= & 295 \mathrm{lb} \mathrm{in}
\end{aligned} \\
& \begin{aligned}
\sigma_{\max } & =\frac{\mathrm{M} \mathrm{c}}{\mathrm{I}} \\
& =\frac{295 \times 1.181}{1.433} \\
& =243 \mathrm{psi}
\end{aligned} \\
& \begin{aligned}
\sigma_{\mathrm{b}}= & \frac{295 \times 0.5905}{1.433} \\
= & 121.5 \mathrm{psi}
\end{aligned}
\end{aligned}
$$

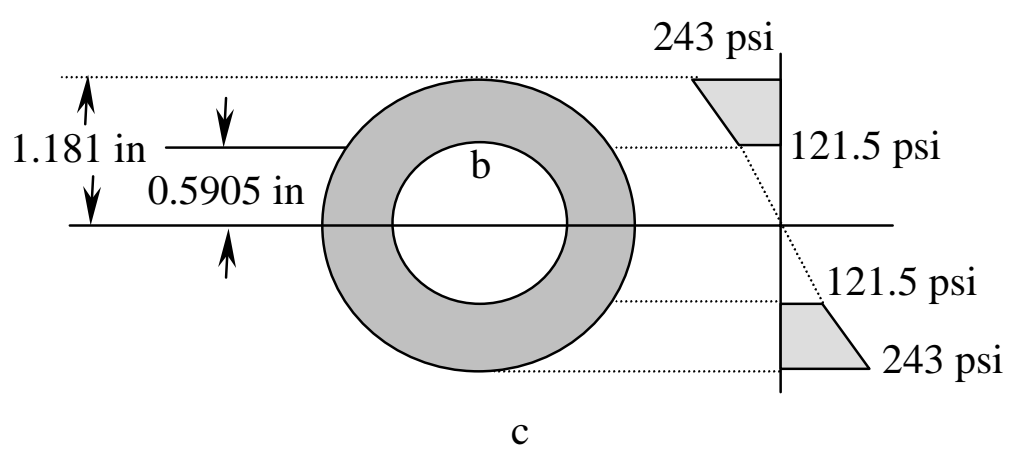


In the bending experiment, the maximum strength is 243 psi with $35.7 \mathrm{lb}$ of loading, which is $41 \%$ of the maximum tensile strength 600 psi in the stress-strain curve in figure 2.1 . So, it can be said that $35.7 \mathrm{lb}$ of loading will not create cracks to the filters.

During the test, the total load applied on each filter included the total weight of the aluminum I-beam and two U-shaped blocks, which weighted together $10.7 \mathrm{lb}$. The applied load was measured by a load cell. The stiffness was calculated from the P - $\Delta$ curve.

\subsection{Instrumentation}

The testing instrumentation used for experiments included

1. $6.5 \mathrm{ft}$. long Steel I-Beam

2. $1.5 \mathrm{ft}$. long Aluminum I-Beam

3. Four Aluminum U-Shaped Blocks

4. 500 lb. Load Cell,

5. Load Cell Display

6. LVDT and Display

The surface of the U-shaped blocks was made spherical, which would provide for the point contact. The LVDT display, model DTR - 451 Digital Transducer Readout (from Schaevitz), was used for the AC output of the LVDT. The LVDT was able to measure $\pm 0.0125 \mathrm{in}$. of deflection. The effective output voltage range of the LVDT was from 200-mV rms. to $1.8 \mathrm{~V}$ rms. During the test, the zero point was set at $900 \mathrm{mV}$ on the LVDT. 
The steel I-beam was used as a base. Two U-shaped blocks and the filter specimen were placed on top of the steel I-beam as the supporting point. The aluminum I-beam and two other U-shaped blocks were bolted together and placed over the filter. The core of the LVDT was connected to a 0.125 -in. bolt that was glued at the center of the filter by using the hotmelt glue. After the hot-melt glue dried (about 20 minutes), the core would be put into the LVDT and adjusted to a proper position by rotating the bolt until the LVDT display gave a reading near $+900 \mathrm{mV}$. A brief sketch of the experimental setup is shown in Figure 5.1.

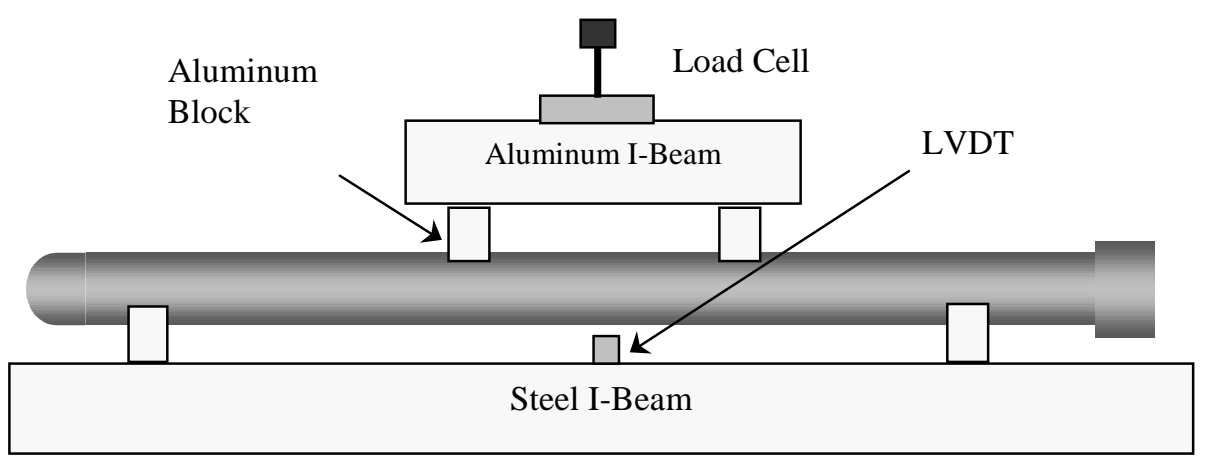

Figure 5.1 Four-Point Behding Experimental Setup 


\subsection{Experimental Procedures}

Each Schumacher filter had a length of 59.625 in. $(1515 \mathrm{~mm})$, an outer diameter of 2.362-in. (60-mm) and an inner diameter of 1.181-in. $(30 \mathrm{~mm})$ with a closed end wall thickness of 1.417 in. $(36 \mathrm{~mm}) . \quad$ The Refractron ceramic candle filter was 59-in. (1499 mm) long, $2.362 \mathrm{in.}(60 \mathrm{~mm})$ in outer diameter and $1.575 \mathrm{in.}(40 \mathrm{~mm})$ in inner diameter with a closed end wall thickness of 0.984-in. (25-mm). Different filters had different weights. Table 5.1 gives the weight and the material properties of each tested filter.

\begin{tabular}{|cccc|}
\hline Specimen & Weight & $\begin{array}{c}\text { Moment } \\
\text { of Inertia(in }\end{array}$ & $\begin{array}{c}\text { Length } \\
\text { (inch) }\end{array}$ \\
\hline A-29 & $6.45 \mathrm{~kg}$ & 1.433 & 59.63 \\
A-23 & $6.42 \mathrm{~kg}$ & 1.433 & 59.63 \\
B-5 & $6.15 \mathrm{~kg}$ & 1.433 & 59.63 \\
B-16 & $6.29 \mathrm{~kg}$ & 1.433 & 59.63 \\
B-27 & $6.29 \mathrm{~kg}$ & 1.433 & 59.63 \\
New & $6.29 \mathrm{~kg}$ & 1.433 & 59.63 \\
Refractron & $4.55 \mathrm{~kg}$ & 1.226 & 59 \\
\hline
\end{tabular}

Table 5.1 Weights and Material Properties of Tested Filters

During each bending test, the filter specimen was pre-loaded to $20.7 \mathrm{lb}$., which included the weight of the aluminum I-beam, and two U-shaped blocks $10.7 \mathrm{lb}$. and an applied 
load of $10 \mathrm{lb}$. The deflection was measured from $20.7 \mathrm{lb}$. to $45.7 \mathrm{lb}$. at each 5-lb. increment. At each loading, the LVDT would give a value of voltage reading, then converted that voltage to a deflection in inches based on the LVDT calibration chart which is shown in Figure 5.2. Each filter was tested repeatedly four times using the same loading range.

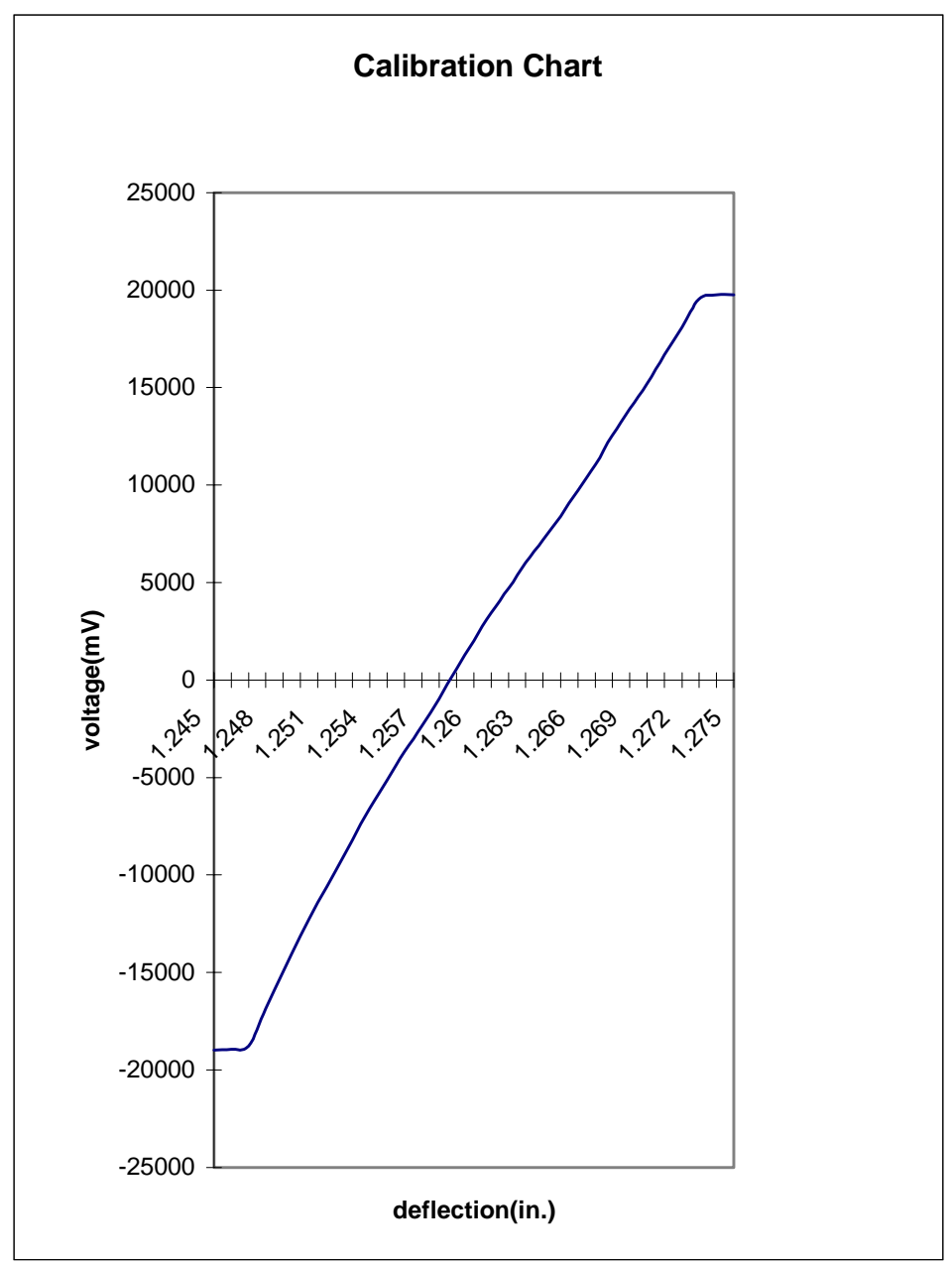

Figure 5.2 LVDT Calibration Chart 


\subsection{Experimental Result}

Figures 5.3 through 5.9 show the relationship between the load and deflection of six Schumacher filters and one Refractron filter. In these figures, the horizontal-axis represents load in pounds, and the vertical-axis represents deflection in inches. These figures show that there is a linear relationship between the load and the deflection for each filter between $92 \mathrm{~N}$ (20.7 lb.) to $159 \mathrm{~N}(35.7 \mathrm{lb}$.). Therefore the amount of deflection corresponding to $92 \mathrm{~N}$ to $159 \mathrm{~N}$ were used to calculate the stiffness and the Young's Modulus of the filters. In Figures 5.5 and 5.8, the $\mathrm{P}-\Delta$ curve after $159 \mathrm{~N}$ (35.7 lb.) became nonlinear. These two filters, A-23 and B-16, were not perfectly straight; therefore there was an influence on the relationship between loads and deflection. Tables 5.2 through 5.8 give the deflections, stiffness and Young's Moduli of these tested filters. The Young's Modulus of each filter is calculated by using the amount of deflection from $92 \mathrm{~N}(20.7 \mathrm{lb}$.) to $159 \mathrm{~N}(35.7 \mathrm{lb}$.). Table 5.9 and 5.10 show the stiffness and Young's Moduli of the tested filters. The average Young's Modulus of A-group and B-group Schumacher filters are $4.1 \times 10^{6} \mathrm{psi}$ and $4.3 \times 10^{6} \mathrm{psi}$ respectively, and the Young's Modulus of new Schumacher filter and Refractron filter is $4.8 \times 10^{6} \mathrm{psi}$ and $5.02 \times 10^{6}$ psi respectively. From the table, it is clear that the Refractron filter had the highest Young's Modulus and the Schumacher A-29 filter had the lowest Young's Modulus. The results obtained from bending tests can indicate the property degradation of filters due to the operation hours. Figure 5.10 gives the distribution of stiffness of these filters. The Refractron filter had the highest stiffness and the Schumacher A-29 filter had the lowest one. 
Static characterization using experimental bending analysis and finite element calculations has been conducted on these specimens. Results indicate that the bending test of the filters can be used as an index to quantify the damage condition of the filters. Consistent deflections have been determined for each of the filters. Schumacher A filters have been found to have greater deflections than Schumacher B filters; which indicates that Schumacher A filters have lower stiffness than B filters.

In the load-deflection curve, the linear curve was from $20.7 \mathrm{lb}$. to $35.7 \mathrm{lb}$. The average deflection of B-group Schumacher filter is 0.0065-inch due to a $15 \mathrm{lb}$. of loading, which was measured from $20.7 \mathrm{lb}$. to $35.7 \mathrm{lb}$. From the FEM result, the deflection at the loading of 35.7 lb. is 0.0062 -inch. It is obvious that the experimental deflection is much greater than the FEM result. The percentage difference between experimental and FEM result is $24.4 \%$. Table 5.11 gives the deflections and comparisons among experimental, theoretical and FEM results. The theoretical and FEM results are based on the $15 \mathrm{lb}$. of loading. The average difference between experimental and theoretical results is $18.8 \%$, and for experimental and FEM results is $17.9 \%$. There are some explanation for these differences between FEM and experimental results. First, each filter has been deflected more than four times, and it may create microcrack during bending. Secondly, the supports of the filter are not fixed, so the filter may move or rotate during bending. Third, the LVDT is a sensitive measured device, the reading may affect when the filter rotates. Finally, the maximum range of the LVDT is \pm 0.0125 (Figure 5.2) with a resolution of \pm 0.001 , which needs to be improved in order to get more accurate results. However, the bending test method seems to be able to correctly indicate the difference of degradation levels among these filters. 


\subsection{Comparison of Vibration and Bending Results}

The Young's Moduli obtained from the vibration tests are larger than the Young's Moduli obtained from the bending tests. The percentage difference of Schumacher A-group filter between vibration and four-point bending analysis is $16.3 \%$, and the difference for Schumacher B-group filters is $16.9 \%$, the differences for new Schumacher and Refractron filters are $17.2 \%$ and $17.7 \%$ respectively. The overall results from the four-point bending test are about $17 \%$ lower than the dynamic results.

The results indicated that there were some error occurred during the four-bending test. Errors can be caused by experiment procedure, setup and instruments. The followings are possibilities for affecting the results. First, the loading frame may be shaken when increasing load. Second, the sensitivity of LVDT is \pm 0.0125 in., which may not indicate the deflection accurately. Third, the spherical surface of supports may rotate the filters when increasing load. Any small influence may cause a small increase in deflection, but it will also contribute a big percentage difference between experiment and theory or between experiment and FEM. The Young's Moduli acquired from the bending test are using the beam bending equations, which may not accurately describe the ceramic candle filter. 


\begin{tabular}{|c|c|c|c|c|}
\hline Load(Ib) & Delf. I (inch) & Delf. II (inch) & Delf. III (inch) & Delf. IV (inch) \\
\hline 20.7 & 0 & 0 & 0 & 0 \\
\hline 25.7 & 0.0023 & 0.0023 & 0.0023 & 0.0024 \\
\hline 30.7 & 0.0047 & 0.0047 & 0.0047 & 0.0049 \\
\hline 35.7 & 0.0073 & 0.0072 & 0.0072 & 0.0073 \\
\hline 40.7 & 0.0097 & 0.0097 & 0.0098 & 0.0098 \\
\hline 45.7 & 0.0122 & 0.0122 & 0.0123 & 0.0121 \\
\hline K (Ib/in) & 2055 & 2083 & 2083 & 2055 \\
\hline E (psi) & $3.92 \mathrm{E}+06$ & $4.00 \mathrm{E}+06$ & $4.00 \mathrm{E}+06$ & $4.00 \mathrm{E}+06$ \\
\hline
\end{tabular}

Table 5.2 Loads and Deflection of Schumacher A-29 Filter

\begin{tabular}{|c|c|c|c|c|}
\hline Load(lb) & Delf. I (inch) & Delf. II (inch) & Delf. III (inch) & Delf. IV (inch) \\
\hline 20.7 & 0 & 0 & 0 & 0 \\
\hline 25.7 & 0.002 & 0.0019 & 0.0018 & 0.0018 \\
\hline 30.7 & 0.0039 & 0.004 & 0.004 & 0.0039 \\
\hline 35.7 & 0.0067 & 0.0067 & 0.0067 & 0.0067 \\
\hline 40.7 & 0.0082 & 0.0084 & 0.0085 & 0.0082 \\
\hline 45.7 & 0.0109 & 0.0109 & 0.011 & 0.0109 \\
\hline K (Ib/in) & 2239 & 2239 & 2239 & 2239 \\
\hline E (psi) & $4.17 \mathrm{E}+06$ & $4.08 \mathrm{E}+06$ & $4.00 \mathrm{E}+06$ & $4.00 \mathrm{E}+06$ \\
\hline
\end{tabular}

Table 5.3 Loads and Deflection of Schumacher A-23 Filter 


\begin{tabular}{|c|c|c|c|c|}
\hline Load(Ib) & Delf. I (inch) & Delf. II (inch) & Delf. III (inch) & Delf. IV (inch) \\
\hline 20.7 & 0 & 0 & 0 & 0 \\
\hline 25.7 & 0.002 & 0.002 & 0.0019 & 0.002 \\
\hline 30.7 & 0.0039 & 0.0039 & 0.0039 & 0.0038 \\
\hline 35.7 & 0.0066 & 0.0067 & 0.0066 & 0.0066 \\
\hline 40.7 & 0.0084 & 0.0084 & 0.0083 & 0.0085 \\
\hline 45.7 & 0.0106 & 0.0105 & 0.0105 & 0.0105 \\
\hline K (Ib/in) & 2273 & 2239 & 2273 & 2273 \\
\hline E (psi) & $4.26 \mathrm{E}+06$ & $4.17 \mathrm{E}+06$ & $4.17 \mathrm{E}+06$ & $4.26 \mathrm{E}+06$ \\
\hline
\end{tabular}

Table 5.4 Loads and Deflection of Schumacher B-5 Filter

\begin{tabular}{|c|c|c|c|c|}
\hline Load(lb) & Delf. I (inch) & Delf. II (inch) & Delf. III (inch) & Delf. IV (inch) \\
\hline 20.7 & 0 & 0 & 0 & 0 \\
\hline 25.7 & 0.0019 & 0.0019 & 0.0019 & 0.002 \\
\hline 30.7 & 0.0038 & 0.0038 & 0.0038 & 0.0038 \\
\hline 35.7 & 0.0065 & 0.0065 & 0.0065 & 0.0065 \\
\hline 40.7 & 0.0082 & 0.008 & 0.0081 & 0.008 \\
\hline 45.7 & 0.0104 & 0.0104 & 0.0105 & 0.0104 \\
\hline K (Ib/in) & 2308 & 2308 & 2308 & 2308 \\
\hline E (psi) & $4.26 \mathrm{E}+06$ & $4.26 \mathrm{E}+06$ & $4.26 \mathrm{E}+06$ & $4.35 \mathrm{E}+06$ \\
\hline
\end{tabular}

Table 5.5 Loads and Deflection of Schumacher B-16 Filter 


\begin{tabular}{|c|r|r|r|r|}
\hline Load(Ib) & Delf. I (inch) & Delf. II (inch) & Delf. III (inch) & Delf. IV (inch) \\
\hline 20.7 & 0 & 0 & 0 & 0 \\
\hline 25.7 & 0.002 & 0.0019 & 0.0019 & 0.0019 \\
\hline 30.7 & 0.0041 & 0.0042 & 0.0042 & 0.0042 \\
\hline 35.7 & 0.0064 & 0.0064 & 0.0064 & 0.0064 \\
\hline 40.7 & 0.0086 & 0.0086 & 0.0085 & 0.0085 \\
\hline 45.7 & 0.0105 & 0.0105 & 0.0106 & 0.0106 \\
\hline K (Ib/in) & 2344 & 2344 & 2344 & 2344 \\
\hline E (psi) & $4.45 \mathrm{E}+06$ & $4.35 \mathrm{E}+06$ & $4.35 \mathrm{E}+06$ & $4.35 \mathrm{E}+06$ \\
\hline
\end{tabular}

Table 5.6 Loads and Deflection of Schumacher B-27 Filter

\begin{tabular}{|c|c|c|c|c|}
\hline Load(lb) & Delf. I (inch) & Delf. II (inch) & Delf. III (inch) & Delf. IV (inch) \\
\hline 20.7 & 0 & 0 & 0 & 0 \\
\hline 25.7 & 0.0018 & 0.0018 & 0.0018 & 0.0018 \\
\hline 30.7 & 0.0036 & 0.0036 & 0.0037 & 0.0036 \\
\hline 35.7 & 0.0059 & 0.0059 & 0.0059 & 0.0059 \\
\hline 40.7 & 0.008 & 0.008 & 0.0081 & 0.0081 \\
\hline 45.7 & 0.0103 & 0.0103 & 0.0104 & 0.0103 \\
\hline K (Ib/in) & 2542 & 2542 & 2542 & 2542 \\
\hline E (psi) & $4.78 \mathrm{E}+06$ & $4.78 \mathrm{E}+06$ & $4.78 \mathrm{E}+06$ & $4.78 \mathrm{E}+06$ \\
\hline
\end{tabular}

Table 5.7 Loads and Deflection of New Schumacher Filter 


\begin{tabular}{|c|c|c|c|c|}
\hline Load(Ib) & Delf. I (inch) & Delf. II (inch) & Delf. III (inch) & Delf. IV (inch) \\
\hline 20.7 & 0 & 0 & 0 & 0 \\
\hline 25.7 & 0.0019 & 0.0019 & 0.0019 & 0.0019 \\
\hline 30.7 & 0.0035 & 0.0036 & 0.0036 & 0.0035 \\
\hline 35.7 & 0.0058 & 0.0058 & 0.0058 & 0.0058 \\
\hline 40.7 & 0.0079 & 0.0079 & 0.0079 & 0.0078 \\
\hline 45.7 & 0.0094 & 0.0096 & 0.0096 & 0.0095 \\
\hline K & 2586 & 2586 & 2586 & 2586 \\
\hline E & $5.02 \mathrm{E}+06$ & $5.02 \mathrm{E}+06$ & $5.02 \mathrm{E}+06$ & $5.02 \mathrm{E}+06$ \\
\hline
\end{tabular}

Table 5.8 Loads and Deflection of Refractron Filter

\begin{tabular}{|c|cccc|}
\hline & \multicolumn{4}{|c|}{$\begin{array}{l}\text { Stiffness } \\
\text { (lb/in) }\end{array}$} \\
Filter & I & II & III & VI \\
\hline A-29 & 2055 & 2083 & 2083 & 2030 \\
A-23 & 2239 & 2239 & 2239 & 2239 \\
B-5 & 2273 & 2239 & 2273 & 2273 \\
B-16 & 2308 & 2308 & 2308 & 2308 \\
B-27 & 2344 & 2344 & 2344 & 2344 \\
New & 2542 & 2542 & 2542 & 2542 \\
Refractron & 2586 & 2586 & 2586 & 2586 \\
\hline
\end{tabular}

Table 5.9 Stiffness of Tested Filters for Four-Point Bending Tests 


\begin{tabular}{|c|c|c|c|c|c|c|c|}
\hline & $\mathrm{A}-29$ & $\mathrm{~A}-23$ & $\mathrm{~B}-5$ & $\mathrm{~B}-16$ & $\mathrm{~B}-27$ & New & Refractron \\
\hline 1 & $3.92 \mathrm{E}+6$ & $4.17 \mathrm{E}+6$ & $4.26 \mathrm{E}+6$ & $4.26 \mathrm{E}+6$ & $4.45 \mathrm{E}+6$ & $4.78 \mathrm{E}+6$ & $5.02 \mathrm{E}+6$ \\
\hline 2 & $4.00 \mathrm{E}+6$ & $4.08 \mathrm{E}+6$ & $4.17 \mathrm{E}+6$ & $4.26 \mathrm{E}+6$ & $4.35 \mathrm{E}+6$ & $4.78 \mathrm{E}+6$ & $5.02 \mathrm{E}+6$ \\
\hline 3 & $4.00 \mathrm{E}+6$ & $4.00 \mathrm{E}+6$ & $4.17 \mathrm{E}+6$ & $4.26 \mathrm{E}+6$ & $4.35 \mathrm{E}+6$ & $4.78 \mathrm{E}+6$ & $5.02 \mathrm{E}+6$ \\
\hline 4 & $4.00 \mathrm{E}+6$ & $4.00 \mathrm{E}+6$ & $4.26 \mathrm{E}+6$ & $4.35 \mathrm{E}+6$ & $4.35 \mathrm{E}+6$ & $4.78 \mathrm{E}+6$ & $5.02 \mathrm{E}+6$ \\
\hline
\end{tabular}

Table 5-10 Young's Moduli (psi) of Schumacher and Refractron Filters from Four-Point Bending Tests

\begin{tabular}{|c|ccc|c|c|}
\hline & \multicolumn{3}{|c|}{ Deflection (in) } & \% Diff & \% Diff \\
Filter & Exp. & Theory & FEM & Exp. \& Theory & Exp. \& FEM \\
\hline A-Group & 0.0069 & 0.00564 & 0.00571 & 18.26 & 17.25 \\
B-Group & 0.0065 & 0.00521 & 0.0053 & 19.85 & 18.46 \\
New Schumacher & 0.0059 & 0.00476 & 0.00481 & 19.32 & 18.47 \\
Refractron & 0.0058 & 0.00476 & 0.0048 & 17.93 & 17.24 \\
\hline
\end{tabular}

Table 5.11 Deflections and Comparisons among Experimental, theoretical and FEM Results 


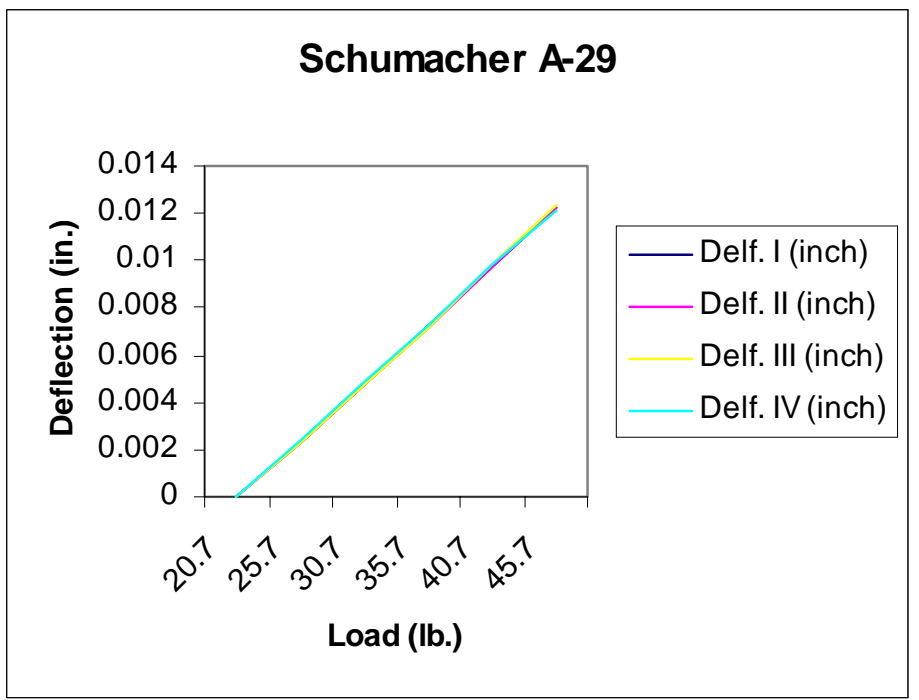

Figure 5.3 Load and Deflection of Schumacher A-29 Filter

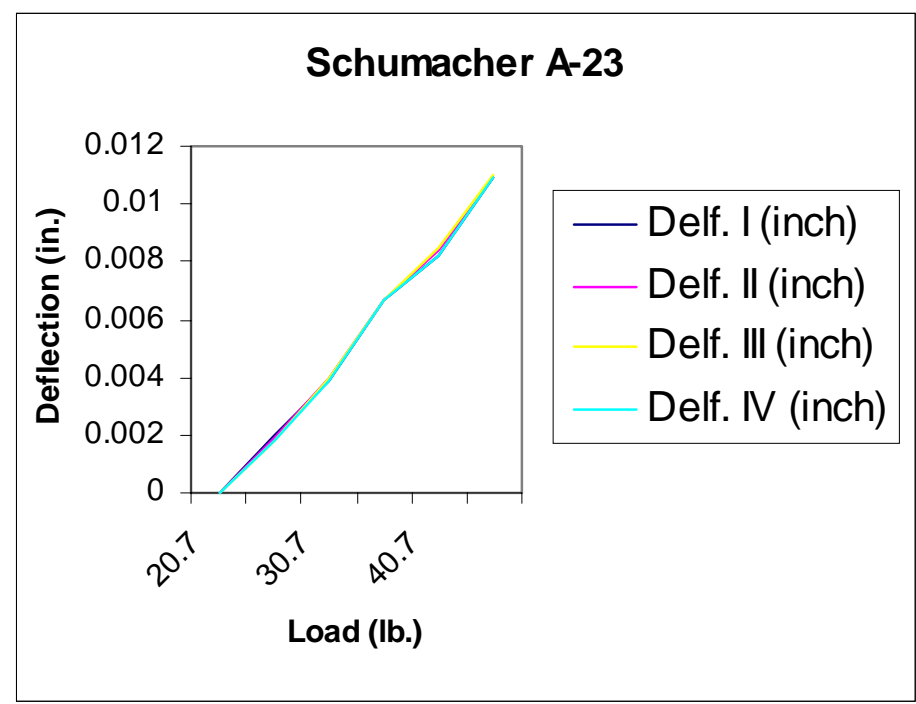

Figure 5.4 Load and Deflection of Schumacher A-23 Filter 


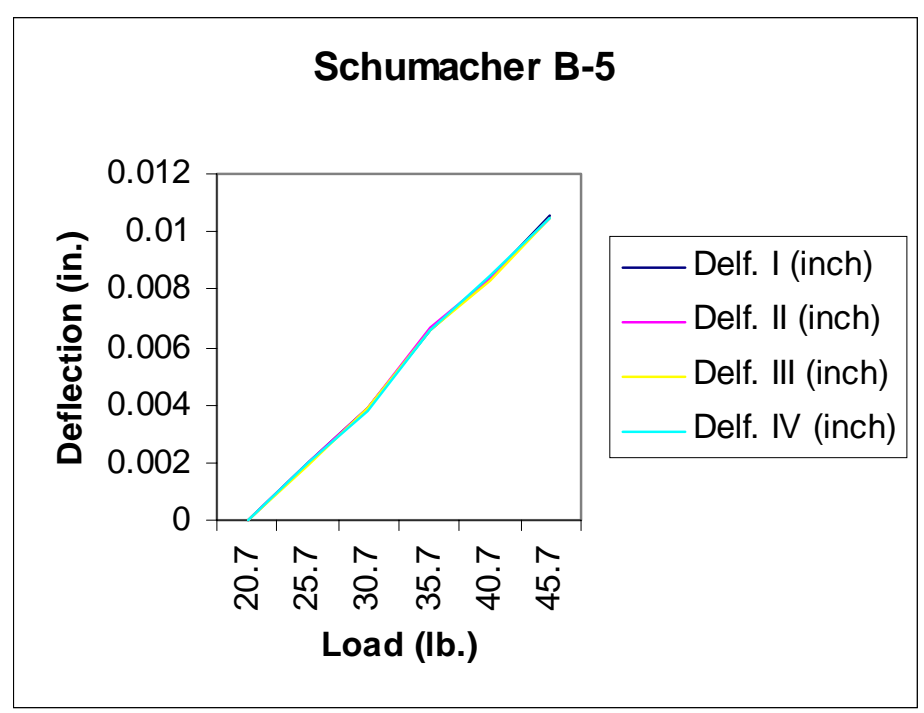

Figure 5.5 Load and Deflection of Schumacher B-5 Filter

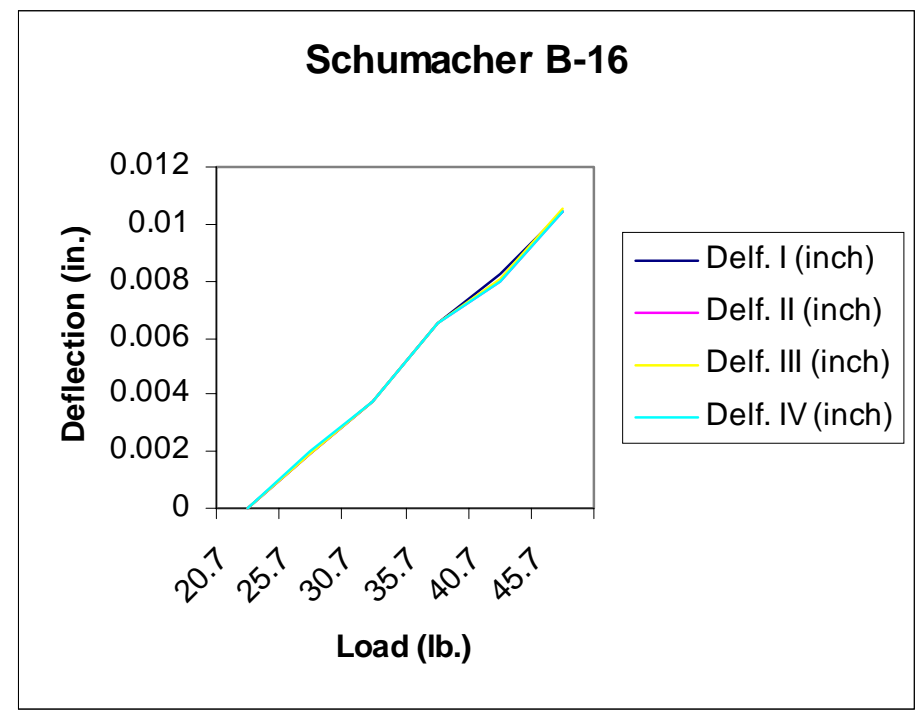

Figure 5.6 Load and Deflection of Schumacher B-16 Filter 


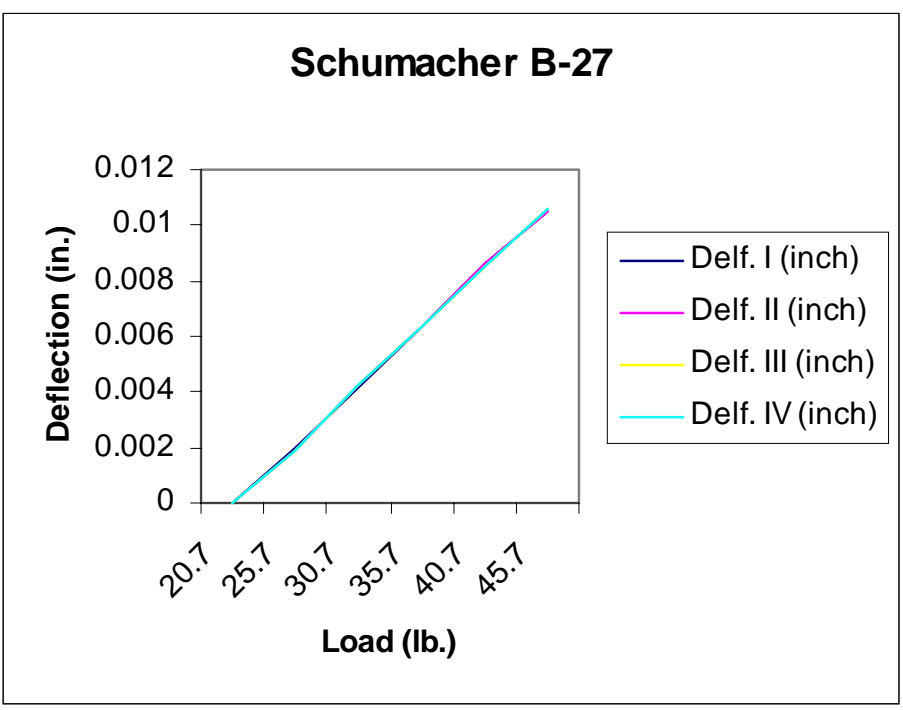

Figure 5.7 Load and Deflection of Schumacher B-27 Filter

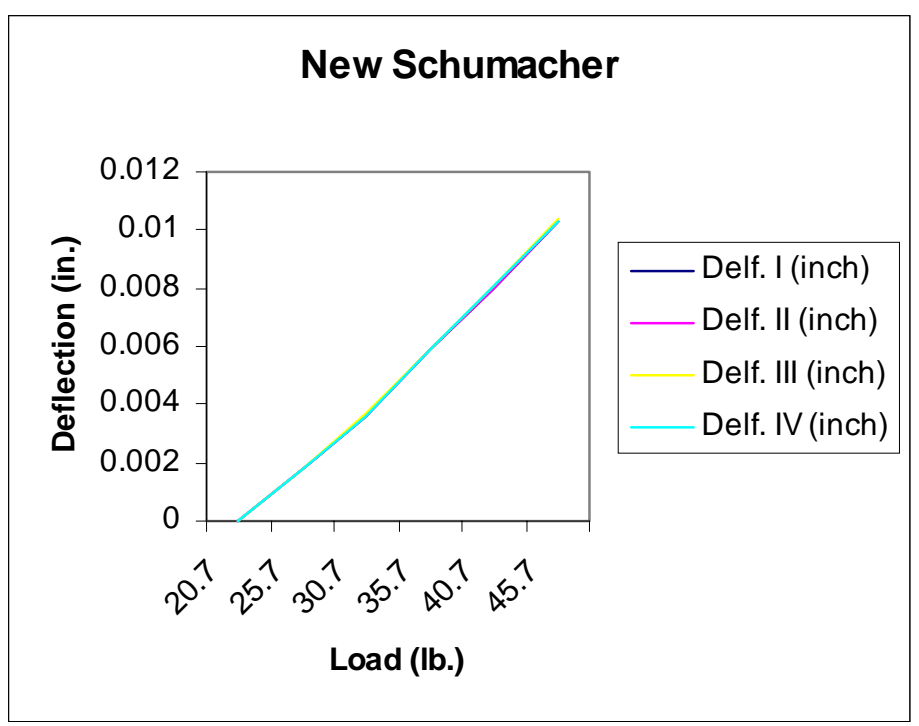

Figure 5.8 Load and Deflection of Schumacher New Filter 


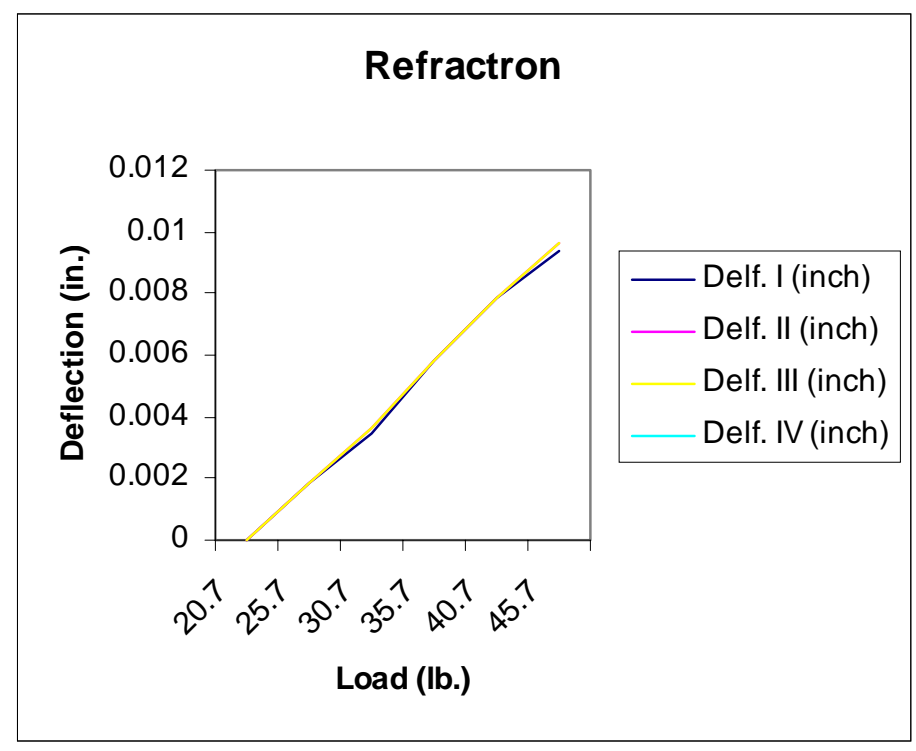

Figure 5.9 Load and Deflection of Refractron Filter

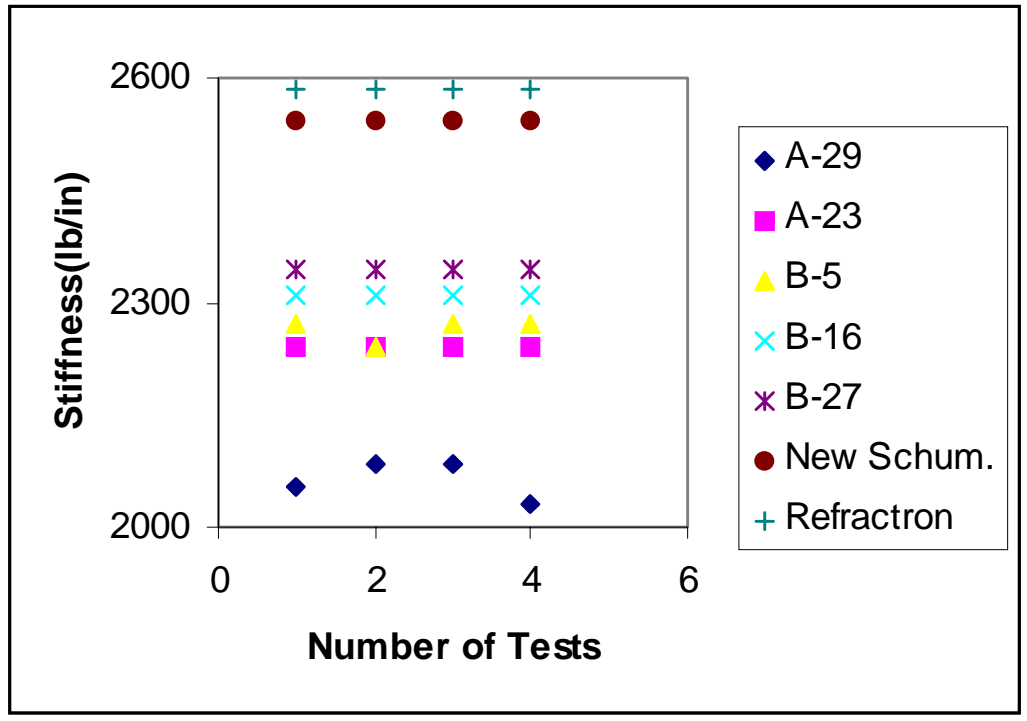

Figure 5.10 Distribution of Stiffness for Bending Tests Filters 


\section{CHAPTER 6}

\section{NUMERICAL ANALYSIS}

\subsection{Introduction}

The finite element formulation of the problem results in a system of simultaneous algebraic equations for solution. In the finite element model, the entire body is in one operation and formulates the equations for each element, and then combines results to obtain the solution. An experimental structure was modeled for simulation test. The simulating results would be used to compare with the experiment results. The following procedures are used to create a model of specimen:

1. Model creation the model was created using the geometric modeling feature. The geometry needed to be specified by inputting the nodal geometry, then the created surface was meshed.

2. Mesh generation the meshing decided corresponds to the points tested, and a node was available at experimental data points, which would yield more accurate result and make comparison with experimental results.

3. Decoding decoding involves assigning element type and material properties of the created model. 


\subsection{Dynamic FEM Analysis}

Dynamic finite element analysis was conducted for the candle filters. Linear modal analysis was performed. Eight-node, three-dimensional, isotropic solid elements were used. The values of Young's modulus, Poisson's ratio and weight density are inputs to the program. No boundary conditions were imposed in order to get the free vibration frequency of the filter. After this, the mode shape analysis is performed.

Two types of models were used for doing the FEM analysis. One model had the dimensions and material properties of Refractron filter. This model was of 59-inch length and consisted of 3390 brick elements with 4985 nodes. The different material properties used for this 59 inch Refractron filter are: Young's modulus, E $=6 \times 10^{6} \mathrm{psi}$, Poisson's ratio $=0.15$, weight density $=0.061 \mathrm{lb} / \mathrm{in}^{3}$. In the second model generated for the Schumacher specimens A and B, same dimensions were used for both groups but only the material properties were changed. The length of the model was 59.625 inch and the model consisted of 3270 brick elements with 4893 nodes. Three-dimensional ceramic filter is shown in figure 6.1. The material properties used for the Schumacher A specimen are: Young's modulus, E $=5 \times 10^{6}$ psi, Poisson's ratio=0.3, weight density $=0.0715 \mathrm{lb} / \mathrm{in}^{3}$, and those for Schumacher B specimen are: Young's modulus, $\mathrm{E}=5.5 \times 10^{6} \mathrm{psi}$, Poisson's ratio $=0.3$ and weight density $=0.0691 \mathrm{lb} / \mathrm{in}^{3}$. The values of Young's modulus and Poisson's ratio were assumed and the weight density was calculated from the measured weight and dimensions of the filter. 


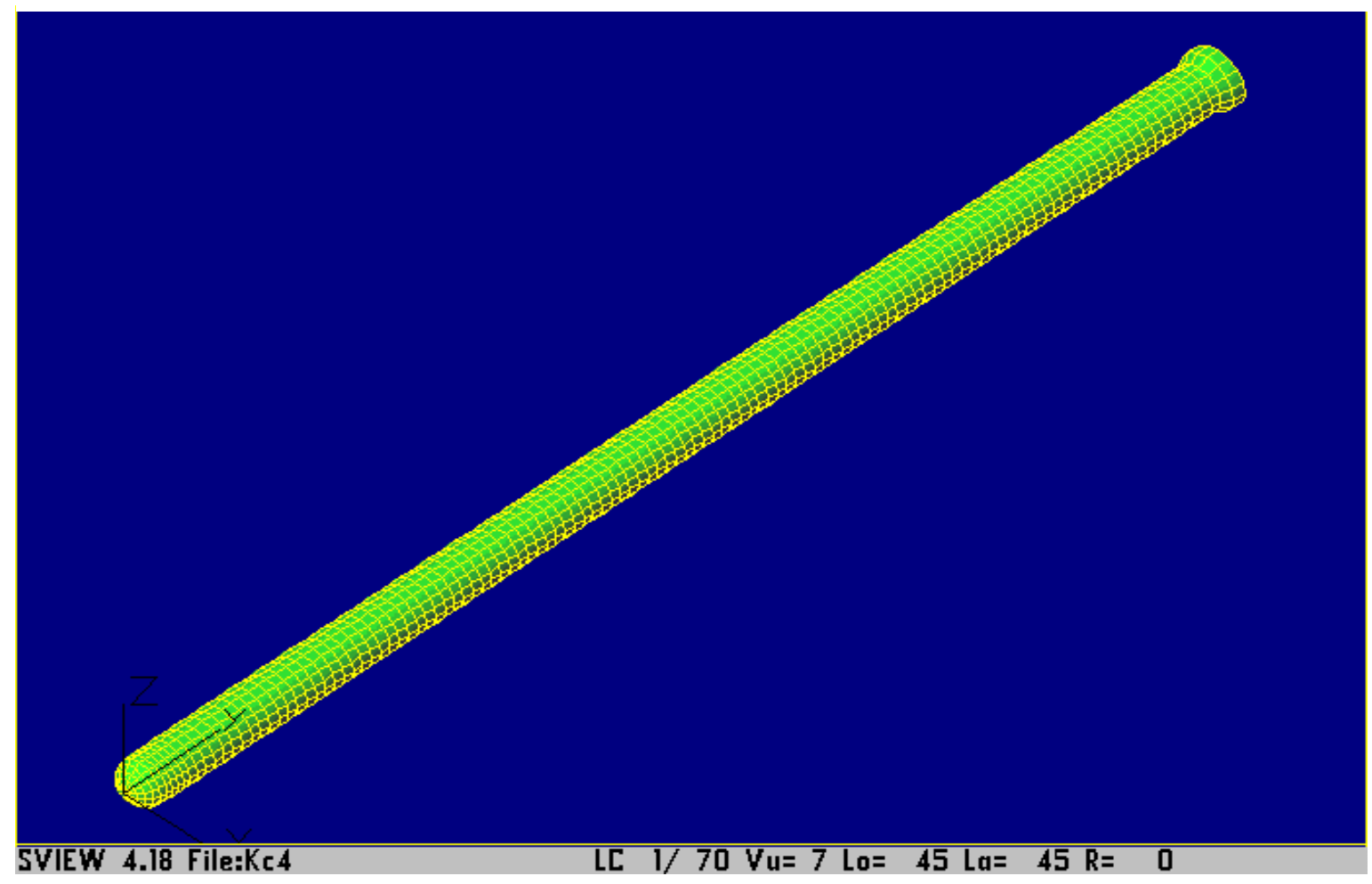

Figure 6.1 Three-dimensional FEM Model of Ceramic Candle Filter 


\subsubsection{Stiffness Effect}

There is a large percentage difference between experimental and FEM results for $\mathrm{E}=6 \times 10^{6}$ psi. For $\mathrm{E}=6.88 \times 10^{6} \mathrm{psi}$, the percentage difference between experimental results and the new results decreases. The comparison of the frequency values at each mode, up to the eighth flexural modes, for the Refractron filter shows that the value of $\mathrm{E}$ equal to $6.88 \times 10^{6} \mathrm{psi}$ is a good approximation of the actual $\mathrm{E}$ value.

The comparison of the percentage difference in frequency for two different $\mathrm{E}$ values, for the Schumacher A and B filter groups were $E=5 \times 10^{6}$ psi and $4.9 \times 10^{6}$ psi for the Schumacher A filter group and $\mathrm{E}=5.5 \times 10^{6} \mathrm{psi}$ and $5.3 \times 10^{6} \mathrm{psi}$ for the Schumacher B filter group. The Poisson's ratio was kept constant at 0.3. The percentage difference in frequency values was calculated between experimental results and the new results. For the Schumacher A group filters, the maximum percentage difference between FEM and experiment is $1.83 \%$ when $\mathrm{E}=5 \times 10^{6}$ psi and equal to $0.80 \%$ when $\mathrm{E}=4.9 \times 10^{6}$ psi. Similarly for the Schumacher B group filters, the maximum percentage difference between FEM and experimental results is $3.0 \%$ when $\mathrm{E}=5.5 \times 10^{6}$ psi and equal to $1.11 \%$ when $\mathrm{E}=5.3 \times 10^{6}$ psi. This shows that the refined values of $E=4.9 \times 10^{6}$ psi for A group filters and $E=5.3 \times 10^{6}$ psi for B group filters are a good approximation of the actual Young's modulus values. 


\subsubsection{Effect of Poisson's Ratio}

The frequency results for the first 8 modes of the Refractron filter, obtained by running different FEM programs using different Poisson's ratio values, were compared. Three different Poisson's ratio values of $0.15,0.20$ and 0.25 were used for the analysis and the Young's modulus was kept the same for all the cases, equals to $6.88 \times 10^{6} \mathrm{psi}$. The maximum percentage difference in frequency when Poisson's ratio is changed from 0.15 to 0.2 is $-0.93 \%$ and the maximum percentage difference in frequency when Poisson's ratio is changed from 0.15 to 0.25 is $-1.19 \%$. Thus it appears that the assumed Poisson's ratio has only minimal effect on the calculated frequency values.

\subsection{Comparison}

\subsubsection{Comparison between Experimental and Theoretical Results}

Equation 3 of Chapter 3 has been used for calculating the theoretical frequency. The moment of inertia has been calculated by considering the cross-section as a hollow tube. The mass per unit length was calculated from the measured weight $(10.09 \mathrm{lbf}$ or $0.026 \mathrm{lbm})$ and the length. Table 6.1 gives frequencies and percentage difference between experimental and Bernoulli-Euler results. The experimental results and theoretical results, calculated using the Bernoulli-Euler beam equation (1), are in good agreement in the first few modes but there is a high percentage difference in the higher modes. 


\begin{tabular}{|ccc|ccc|ccc|}
\hline \multicolumn{3}{|c|}{$\begin{array}{c}\text { Refractron Filter } \\
\text { Filter }\end{array}$} & \multicolumn{3}{|c|}{ Schumacher Filter } & \multicolumn{3}{|c|}{ Achumacher Filter } \\
Exp. & Bernou. & \% Diff. & Exp. & Bernou. & \% Diff. & Exp. & B-Group \\
\hline 142.5 & 141.2 & -0.92 & 102.1 & 106.62 & 4.24 & 108.38 & 112.83 & 3.94 \\
387.5 & 389.3 & 0.46 & 276.9 & 293.9 & 5.78 & 292.15 & 311.02 & 6.07 \\
745 & 763.2 & 2.38 & 538.13 & 576.18 & 6.60 & 565.45 & 609.73 & 7.26 \\
1205 & 1261.6 & 4.49 & 881.07 & 952.44 & 7.49 & 924.56 & 1007.91 & 8.27 \\
1752.5 & 1884.7 & 7.01 & 1286.25 & 1422.78 & 9.60 & 1353.19 & 1505.64 & 10.13 \\
2372.5 & 2632.3 & 9.87 & 1751.47 & 1987.2 & 11.86 & 1843.44 & 2102.92 & 12.34 \\
3067.5 & 3504.5 & 12.47 & 2271.12 & 2645.67 & 14.16 & 2397.06 & 2799.73 & 14.38 \\
3792.5 & 4501.4 & 15.75 & 2830.89 & 3398.22 & 16.69 & 2991.25 & 3596.1 & 16.82 \\
\hline
\end{tabular}

Table 6.1 Frequencies and Percentage Difference of experimental and Bernoulli-Euler Results

A comparison between the experimental and theoretical results for Schumacher filter groups A and B was conducted by using the same procedure described above for the Refractron filter. As in the case of the Refractron filters, in the higher modes, there is a large percentage difference in the frequency values obtained from the experiments and calculated from the Bernoulli-Euler beam equation.

FEM analysis was conducted to study the reason for the high deviation between the experimental and theoretical frequency results in the higher modes. The high deviation between the experimental and theoretical frequency results in the higher modes could be because of neglecting the shear effect in the Bernoulli-Euler beam equation. At higher modes, the beam equation results are higher than the experimental results, but the FEM result with high $\mathrm{G}$ value closely follows the beam equation curve even in the higher modes. 


\subsubsection{Comparison between Experimental and FEM Results}

Table 6.2 shows a comparison between the experimental and Finite Element (FE) frequency results for the Refractron filter. The refined value of Young's modulus has been used to calculate the FEM results. It is seen from the table that the maximum percentage difference in the frequency results of the experiments and FEM is $-1.31 \%$.

\begin{tabular}{|c|c|c|c|}
\hline MODE & EXPT. & $\begin{array}{c}\text { FEM } \\
\text { E=6.88E6 }\end{array}$ & \% DIFF. \\
& $($ Hz $)$ & $\begin{array}{c}\text { ( PSI }) \\
\text { v=0.15 }\end{array}$ & \\
\hline 1 & 142.5 & 140.63 & -1.31 \\
2 & 387.5 & 384.57 & -0.76 \\
3 & 745 & 743.29 & -0.23 \\
4 & 1205 & 1204.58 & -0.03 \\
5 & 1752.5 & 1755.88 & 0.19 \\
6 & 2372.5 & 2383.89 & 0.48 \\
7 & 3067.5 & 3075.83 & 0.27 \\
8 & 3792.5 & 3819.93 & 0.72 \\
\hline
\end{tabular}

Table 6.2 Comparison of Experimental and FEM Frequencies for Refractron Filter 
Table 6.3 shows a comparison between the experimental and Finite Element (FE) frequency results for Schumacher specimens A and B. For the Schumacher specimens of group A, the maximum percentage difference between experimental and FEM results is $0.81 \%$ while for the Schumacher specimens of group B the maximum percentage difference between experimental and FEM results is $1.11 \%$.

Figure 6.2 and 6.3 summarize the frequency shift between group A and group B specimens in terms of percentage difference respectively. In this figure, the $\mathrm{X}$-axis represents the vibration mode number and the $\mathrm{Y}$-axis represents the frequency of vibration in Hertz. It is seen from the figure that both the experimental and FEM results follow the same curve.

\begin{tabular}{|c|c|c|c|c|c|c|}
\hline MODE & $\begin{array}{c}\text { EXPT. } \\
\text { A-Group } \\
(\mathbf{H z})\end{array}$ & $\begin{array}{c}\text { FEM } \\
\text { E=4.9E6 } \\
(\text { ps } \mathbf{i}) \\
\mathbf{v = 0 . 3}\end{array}$ & \% DIFF. & $\begin{array}{c}\text { EXPT. } \\
\text { B-Group } \\
(\mathbf{H z})\end{array}$ & $\begin{array}{c}\text { FEM } \\
\text { E=5.3E6 } \\
(\mathbf{p s i}) \\
\mathbf{v = \mathbf { 0 . 3 }}\end{array}$ & \% DIFF. \\
\hline 1 & 102.054 & 102.11329 & 0.058097 & 108.375 & 108.03056 & -0.31782 \\
2 & 276.994 & 279.22515 & 0.8054883 & 292.152 & 295.40788 & 1.1144471 \\
3 & 538.125 & 540.25504 & 0.3958256 & 565.445 & 571.54597 & 1.0789684 \\
4 & 881.071 & 877.27344 & -0.431016 & 924.563 & 928.08119 & 0.3805243 \\
5 & 1286.25 & 1282.1826 & -0.316223 & 1353.187 & 1356.4437 & 0.2406702 \\
6 & 1751.473 & 1746.2709 & -0.297012 & 1843.437 & 1847.3668 & 0.2131774 \\
7 & 2271.116 & 2261.0446 & -0.443454 & 2397.062 & 2391.9861 & -0.211755 \\
8 & 2830.893 & 2818.4852 & -0.4383 & 2991.25 & 2981.7613 & -0.317215 \\
\hline
\end{tabular}

Table 6.3 Comparison of Experimental and FEM Frequencies for A-Group and B-Group Schumacher Filters 


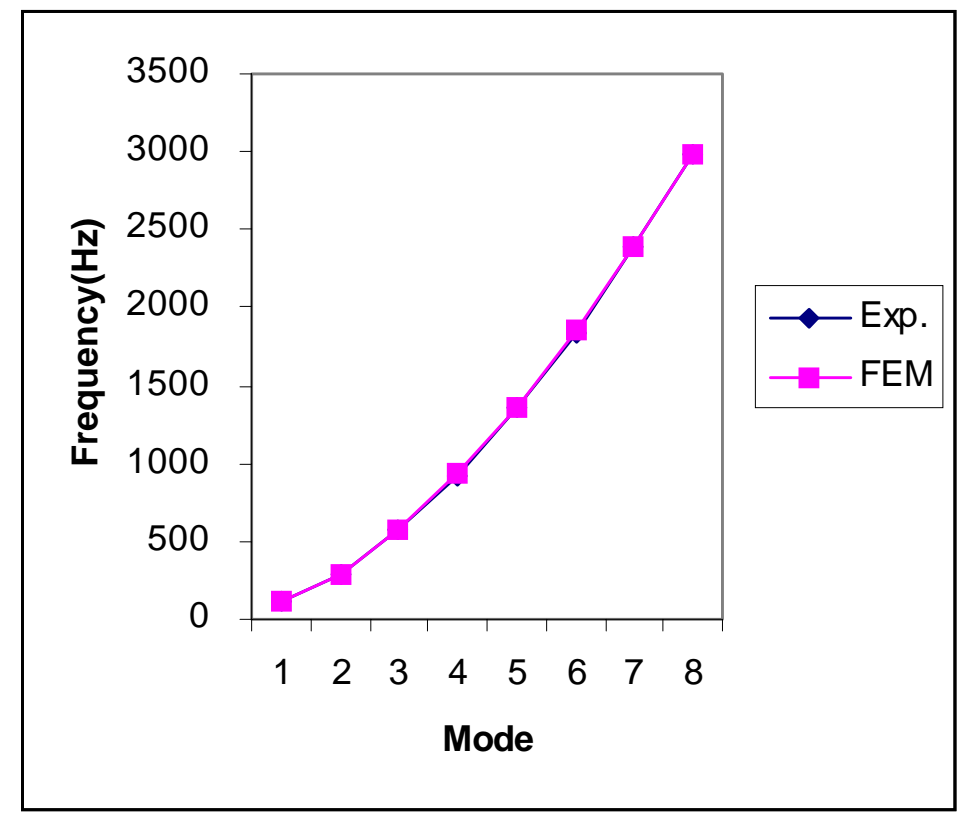

Figure 6.2 Comparison of Experimental and FEM Frequency for A-Group Schumacher Filter

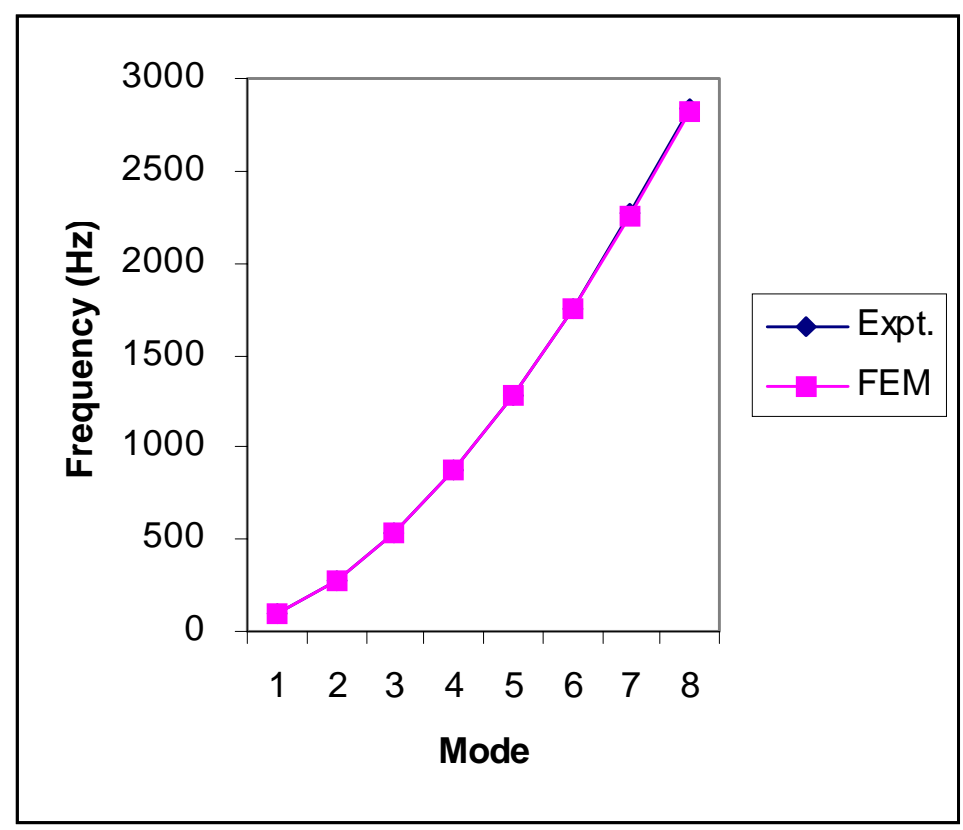

Figure 6.3 Comparison of Experimental and FEM Frequency for B-Group Schumacher Filter 


\subsection{Damage Analysis and FEM Analysis on A Broken Filter}

In order to study the effect of local damage in the filter on the frequency response of the filter, FE models with different amounts of localized damage zones were analyzed. Three cases were studied: a localized damage zone of $4.8 \%, 10.6 \%$, and $100 \%$ of the total length of the filter. The damage zone was located at midspan of the filter. This study was performed on the Refractron FE model. The damage was simulated in the FEM model by reducing the Young's modulus for some portion of the length of the filter. For a damage zone of $4.8 \%$ and $10.6 \%$ of the length of the filter, a Young's Modulus (E) value for the zone was taken as 50\%

of the original $\mathrm{E}$ value $\left(6.88 \times 10^{6} \mathrm{psi}\right)$. For the case with damage zone over the entire length of the filter, the $\mathrm{E}$ value for the zone was taken as $90 \%$ of the original $\mathrm{E}$ value.

For a damage zone of $10.6 \%$ of length and with a $50 \%$ stiffness reduction, a similar trend is observed, the deviation in frequency is high in the odd modes and low in the even modes. The trend continues up to the fourth mode and then attains a constant deviation of about 5\%. For a damage zone throughout the length (100\%) and a stiffness reduction of $10 \%$, there is a constant deviation of about $5.5 \%$ in all the modes. Since a constant deviation in frequency is also observed between Schumacher A and B group specimens in all the modes. It appears that these two groups of filters may also have been subjected to a uniform loss in stiffness over the entire length of the filter rather than a localized damage. These results indicate the feasibility of using the vibration frequencies to predict the damage location.

A model of damaged A-group Schumacher filter was constructed for the FEM analysis. It was the Schumacher A-4 filter specimen, which has the Young's Modulus E = 4.9 $\mathrm{x} 10^{6} \mathrm{psi}$, Poisson ratio $=0.3$, weight density $=0.0715 \mathrm{lb} / \mathrm{in}^{3}$ and length $=59.625 \mathrm{in}$. The 
epoxy glue was used to connect two broken pieces of this filter. It has material properties of Young's Modulus E $=1 \times 10^{7} \mathrm{psi}$, Poisson ratio $=0.3$ and weight density $=0.1 \mathrm{lb} / \mathrm{in}^{3} . \quad$ The epoxy glue was applied over the crack and at 0.7 inches to either side of the crack. The repaired Schumacher filter FEM model is shown in figure 6.4

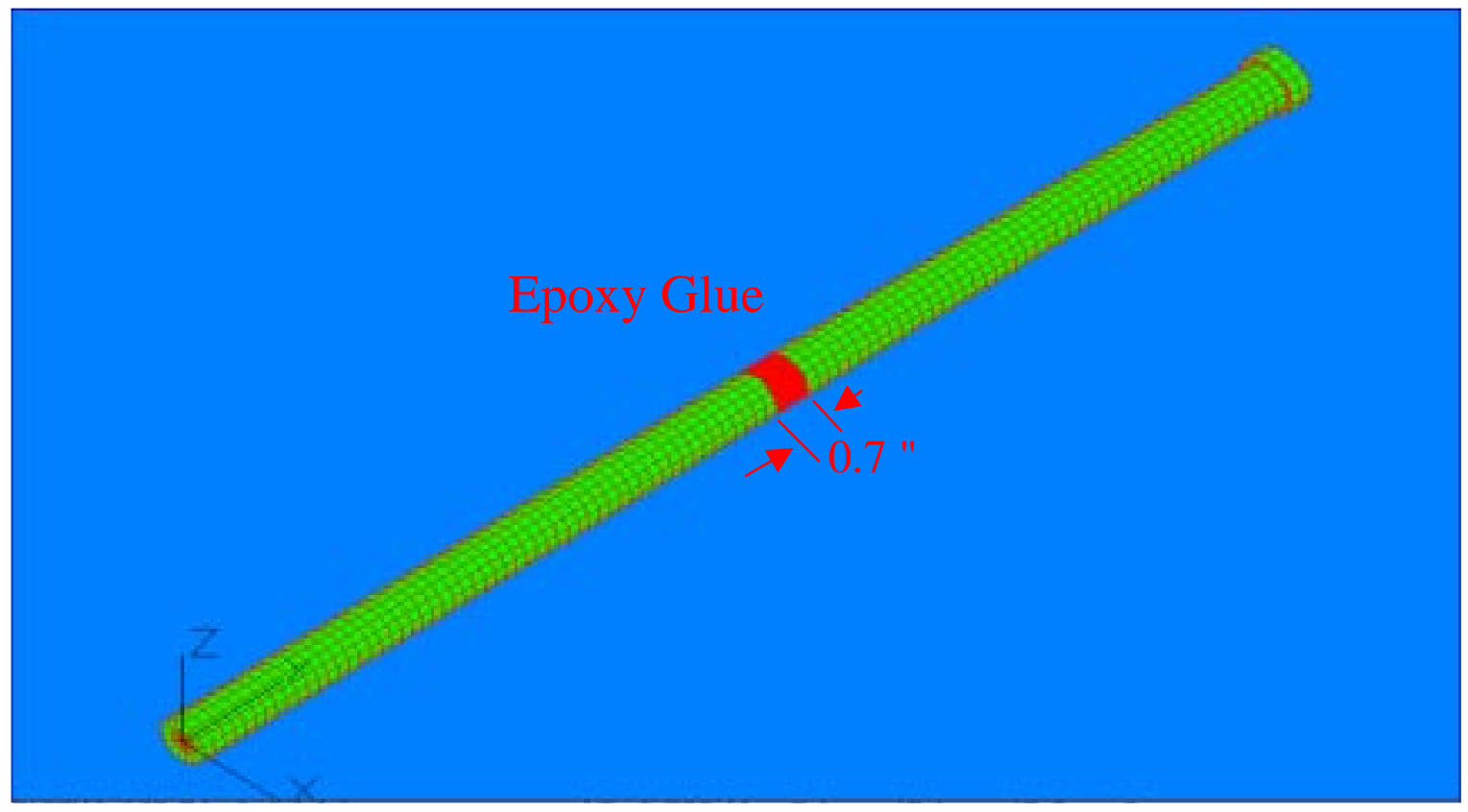

Figure 6.4 FEM Model of Repaired A-4 Schumacher Filter

Figure 6.5 shows the eighth mode vibration of the repaired filter. The darker area near the center was assumed to be the damage location and repaired with epoxy glue. The eighth 
mode frequencies obtained from the FEM analysis are $2918.5 \mathrm{~Hz}$ before the filter was broken and $2872.7 \mathrm{~Hz}$ after it was repaired, and the eighth mode frequencies obtained from the experimental result are $2905 \mathrm{~Hz}$ before it was broken and $3007 \mathrm{~Hz}$ after it was repaired. The percentage differences between the experimental and Finite Element Method (FEM) results are $0.46 \%$ before the filter was broken and $4.5 \%$ after the filter was repaired.

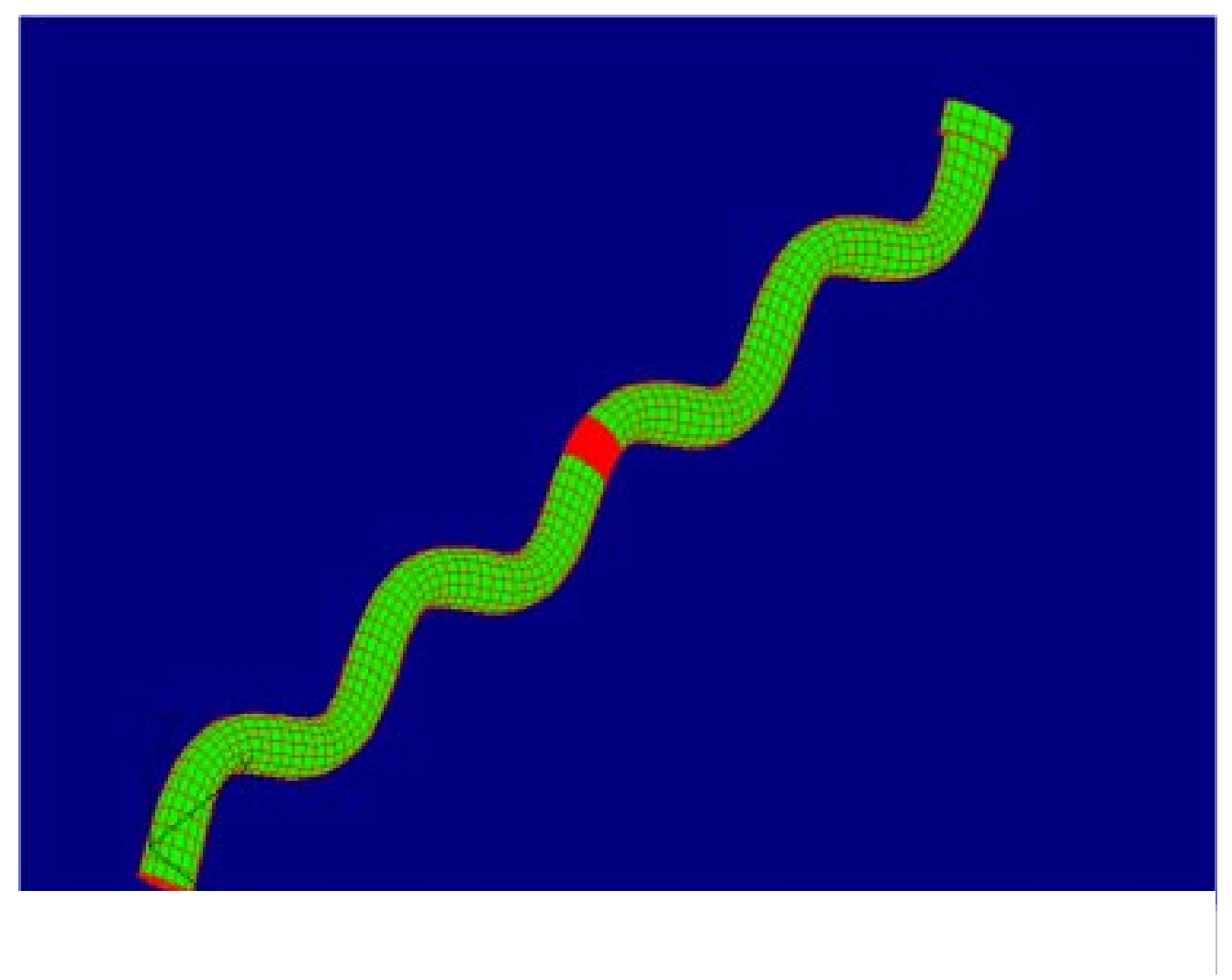

Figure 6.5 The Eighth Vibration Mode for A-4 Repaired Schumacher Filter 


\subsection{Static FEM Analysis}

Static finite element analysis was conducted on the filters. Linear stress static analysis was performed. A B-group model from the Schumacher filters was used for demonstrating the FEM analysis. The material properties used for the Schumacher B specimen are: Young's Modulus $(E)=5.3 \times 10^{6}$ psi, Poisson's ratio $=0.3$, weight density $=$ $0.069 \mathrm{lb} / \mathrm{in}^{3}$.

The filter for the finite element analysis was constructed in a 3-D model. Four boundary conditions were imposed on the filter in order to conduct the four-point bending test. Two 17.85-lb loads were applied on the filter at locations of $22.55 \mathrm{in}$. and $36.64 \mathrm{in}$. Two bottom hinge supports were set at locations of 3.38 in. and 56.4 in. The model was 59- in. long and consisted of 3270 brick element with 4893 nodes, which is shown in figure 6.1 .

The FEM results show that the maximum deflection at the center of the filter was $0.0062 \mathrm{in}$. when $35.7 \mathrm{lb}$. of load was applied. The stress at the center was 220 psi. The deflection obtained from the FEM analysis is much lower than the results obtained from the experimental tests, which are listed on Tables 5.2 through 5.8. The error may be attributed from the experimental environment such as the support settlement, vibration of the floor and the air circulation. It is noted that the LVDT can not accurately reflect the change due to these environmental influences during the bending test. 


\section{CHAPTER 7}

\section{DISCUSSIONS}

In order to better understand the results in vibration tests and bending tests on ceramic candle filters, the following three questions were studied:

1. The difference between the experimental and theoretical frequencies in higher mode is becoming larger possibly due to the negligence of the shear effect in the Bernoulli beam equation. Is there a way to consider the shear effect in the beam vibration analysis?

The Bernoulli-Euler beam equation was applied in the previous vibration research. The effects of rotary inertia and shear deformations were neglected in this equation. So, the difference between experimental and theoretical frequencies in higher modes is becoming larger because of neglecting of shear effect in the Bernoulli beam equation. Table 7.1 gives frequencies and percentage difference between FEM and Bernoulli-Euler results.

In the free-free vibration test, the filter performs not only a vibrating motion, but also rotation and effect from shear stress. The angle of rotation is corresponding to angular velocity and angular acceleration, which relates to the slope of the deflection curve. Also moments needs to be considered in the dynamic situation, which will cause the elements of structure to deform. In the free-free vibration experiment, the filter was dangled in a tri-pod and would rotate when a vibrating motion continued. The lower parts of the filter will have a larger rotating movement. When a filter becomes flexural due to vibration, it will also have affects 
from bending moment and shear force. In order to consider the effects of shear and rotary inertia, Timoshenko equations can be applied in a vibration test as shown below. (Timoshenko and Weaver, 1972).

$$
\begin{aligned}
& \mathrm{EI} \frac{\partial^{4} y}{\partial_{x^{4}}}+\rho_{A} \frac{\partial^{2} \mathrm{y}}{\partial t^{2}}=\rho_{I}\left(1+\frac{\mathrm{E}}{\boldsymbol{k}^{\prime} \mathrm{G}}\right) \frac{\partial^{4} y}{\partial x^{2} \partial^{2}}+\frac{\rho^{2} I}{k^{\prime} \mathrm{G}} \frac{\partial^{4} y}{\partial t^{4}}=0 \\
& K^{\prime}=\frac{6(1+v)\left(1+\mathbf{m}^{2}\right)^{2}}{(7+6 v)\left(1+m^{2}\right)^{2}+(20+12 v) m^{2}}
\end{aligned}
$$

\section{Where $\mathbf{m}=\mathbf{r}_{\mathbf{o}} / \mathbf{r}_{\mathbf{i}}$}

$k^{\prime}$ : numerical factor depending on the shape of cross section

$\rho:$ mass density

$A$ : area of cross section

$\mathrm{G}$ : modulus of rigidity

$\mathrm{r}_{\mathrm{o}}$ : outside diameter

$r_{i}$ : inside diameter

v : Poisson ratio 


\begin{tabular}{|c|c|c|c|c|c|}
\hline \multicolumn{2}{|c|}{$\begin{array}{r}\text { A-group Schumacher } \\
\text { Frequency }(\mathrm{Hz})\end{array}$} & $(1750 \mathrm{hr})$. & \multicolumn{2}{|c|}{$\begin{array}{c}\text { B-group Schumacher } \\
\text { Frequency }(\mathrm{Hz})\end{array}$} & $(460 \mathrm{hr})$. \\
\hline FEM & Bernoulli & $\%$ Diff & FEM & Bernoulli & $\%$ Diff \\
\hline 102.11 & 106.62 & 4.23 & 108.03 & 112.83 & 4.25 \\
\hline 279.23 & 293.9 & 4.99 & 295.41 & 311.02 & 5.02 \\
\hline 540.26 & 576.18 & 6.23 & 572.55 & 609.73 & 6.10 \\
\hline 877.27 & 952.44 & 7.89 & 928.08 & 1007.91 & 7.92 \\
\hline 1281.18 & 1422.79 & 9.95 & 1356.44 & 1505.64 & 9.91 \\
\hline 1746.27 & 1987.2 & 12.12 & 1847.37 & 2102.92 & 12.15 \\
\hline 2261.05 & 2645.67 & 14.54 & 2391.99 & 2799.73 & 14.56 \\
\hline 2818.48 & 3398.22 & 17.06 & 2981.76 & 3596.1 & 17.08 \\
\hline
\end{tabular}

Table 7.1 Frequencies and Percentage Difference between FEM and Bernoulli Euler Results

To apply the Timoshenko equation to the vibration research, calculations were executed by using a Fortran program. The program is written by Alejandro Kiriakidis (Kiriakidis, 1998), a research assistant at West Virginia University. The following values were input to the Fortran program to calculate the Timoshenko equation, $\mathrm{E}=4.9 \times 10^{6}$ psi. $\rho=0.0715$ $\mathrm{lb} / \mathrm{in}^{3}, \mathrm{~A}=3.27 \mathrm{in}^{2}, k^{\prime}=0.62, \mathrm{G}=1.89 \times 10^{6} \mathrm{psi}$ for A-group filters, $\mathrm{E}=5.3 \times 10^{6}$ psi. $\rho=0.0691$ $\mathrm{lb} / \mathrm{in}^{3}, \mathrm{~A}=3.27 \mathrm{in}^{2}, k^{\prime}=0.62, \mathrm{G}=2.04 \times 10^{6} \mathrm{psi}$ for B-group filters. The frequency comparison of FEM and Timoshenko results is shown in Table 7.2.

For Schumacher A-group filters, the percentage differences of frequencies at the eighth mode between Bernoulli-Euler and FEM calculation, and Timoshenko and FEM calculation are $17.06 \%$ and $1.75 \%$ respectively. The percentage differences for Schumacher B-group filter at the eighth mode between Bernoulli-Euler and FEM calculation, and Timoshenko and 
FEM calculation are $17.08 \%$ and $1.9 \%$ respectively. Table 7.2 gives frequency results from Timoshenko and FEM results.

The analysis using Timoshenko equation is more accurate than Bernoulli-Euler analysis. The Timoshenko equation can be suggested to apply for future research in free-free vibration analysis.

\begin{tabular}{|c|c|c|c|c|c|}
\hline \multicolumn{2}{|c|}{$\begin{array}{r}\text { A-Group Schımacher } \\
\text { Frequency }(\mathrm{Hz})\end{array}$} & $(1750 \mathrm{hr})$. & \multicolumn{2}{|c|}{$\begin{array}{l}\text { B-Group Schumacher } \\
\text { Frequency }(\mathrm{Hz})\end{array}$} & (460 hr.) \\
\hline FEM & Timos. & $\%$ Diff & FEM & Timos. & $\%$ Diff \\
\hline 102.11 & 102.31 & 0.20 & 108.03 & 108.11 & 0.07 \\
\hline 279.23 & 277.35 & -0.68 & 295.41 & 293.54 & -0.64 \\
\hline 540.26 & 540.14 & -0.02 & 572.55 & 567.25 & -0.93 \\
\hline 877.27 & 875.35 & -0.22 & 928.08 & 924.89 & -0.34 \\
\hline 1281.18 & 1314.54 & 2.54 & 1356.44 & 1396.63 & 2.88 \\
\hline 1746.27 & 1787.32 & 2.30 & 1847.37 & 1898.27 & 2.68 \\
\hline 2261.05 & 2299.89 & 1.69 & 2391.99 & 2449.56 & 2.35 \\
\hline 2818.49 & 2868.65 & 1.75 & 2981.76 & 3039.49 & 1.90 \\
\hline
\end{tabular}

Table 7.2 Frequencies Using Different Method for A-group and B-Group Schumacher Filters 
2. In the experiment and analysis of the damaged filter, there are some difference between the FEM and experimental frequencies. The FEM calculation can be refined to obtain a better approximation of the material properties to represent the repaired A4 filter. How would the zone damage assumed in the FEM relate to cracks on the filter? If a crack occurs at a certain location on the filter it will cause a loss of stiffness in a zone around the crack? How can one determine the size of the damaged zone?

The A-4 Schumacher ceramic filter was broken into two pieces during bending test. It was connected together using epoxy glue. The glue was smeared on the surface of cross section and 0.7-inch around the crack. The extent of damage area can not be determined. Also, the material property of epoxy glue is unknown. In the finite element analysis on the damage filter, the Young's modulus of epoxy glue and the extent of damaged area were assumed. So, the frequency difference between FEM and experimental tests for A-4 damaged Schumacher filter is because of uncertainties about the extent of damaged area, and properties of epoxy glue. Figure 7.1 shows the FEM model of A-4 Schumacher filter after applying epoxy glue and affected area. 


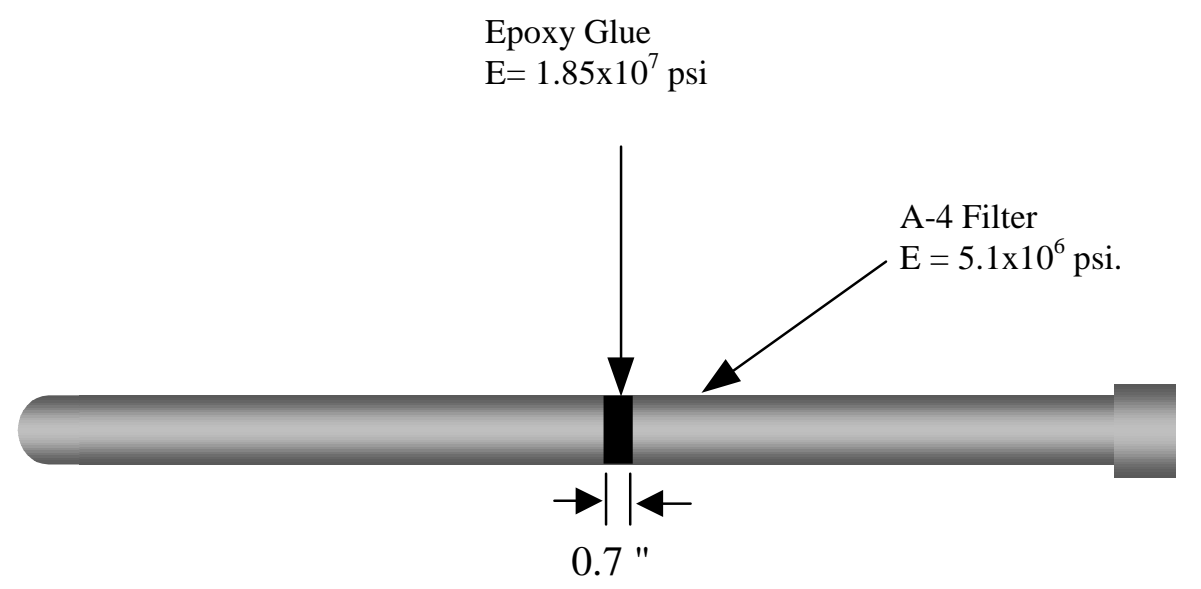

Figure 7.1 FEM Model of A-4 Repaired Schumacher Filter

The material characteristic of the A-4 Schumacher filter is higher than an average Agroup Schumacher filter. Its Young's modulus is $E=5.1 \times 10^{6} \mathrm{psi}$. In the FEM test, the assumption of material property of epoxy glue and the extent of damaged area were first assumed at $\mathrm{E}=1 \times 10^{7} \mathrm{psi}$ and 1 -inch. The FEM result was obviously not close to the experimental result (Chapter 6). In order to acquire better results between finite element method and experiment, the assumption was revised until frequencies of two tests were close. The FEM results were close to experimental results, when the assumption was set at $\mathrm{E}=$ $1.85 \times 10^{7} \mathrm{psi}$ for the epoxy glue and the damage zone is 0.7 in wide. The Young's modulus of damage zone was same as A-4 Schumacher filter $E=5.1 \times 10^{6}$ psi. Table 7.3 gives experimental and FEM results of A-4 broken Schumacher filter. 


\begin{tabular}{|ccc|}
\hline A4 & \multicolumn{3}{c|}{ Repaired Schumacher Filter } \\
Expe.(Hz) & FEM (Hz) & \% Diff. \\
\hline 105.53 & 105.32 & 0.19 \\
290.65 & 290.18 & 0.16 \\
565.87 & 562.06 & 0.67 \\
924.32 & 915.61 & 0.94 \\
1352.76 & 1336.74 & 1.18 \\
1847.93 & 1827.11 & 1.13 \\
2408.82 & 2375.92 & 1.37 \\
3007 & 2959.96 & 1.55 \\
\hline
\end{tabular}

Table 7.3 Frequency Comparison of A-4 Repaired Schumacher Filter

In the first three modes, frequencies are closer than other modes between FEM and experimental result. The average difference is $0.89 \%$. If the Young's modulus of epoxy glue is $1.85 \times 10^{7} \mathrm{psi}$, then the extent of damaged area is same as the area applied epoxy glue. In the FEM analysis, the damage area was assumed in between the crack. The crack on the A-4 filter is at 28-inch from its head. So, the extent of damaged area is from the location of 27.65inch to 28.35-inch.

A crack in a structure will change the vibrational characteristics such as resonant frequencies and mode shape. It is typically related with a stiffness reduction at the vicinity of the crack. Mode shapes curvature can be used to detect the damage location in a structure. A reduction of stiffness will lead to an increase in curvature. It is to estimate numerically from the displacement mode shape with a different approximation. Differences in mode shapes are 
shown to be able to locate the cracked region.

In order to compare the mode shapes for damage detection, the mode shapes need to be normalized. The normalized procedure was to scale the mode shape vector, so that its largest modal amplitude has unit magnitude. The process of normalization is comparatively easier to yield sufficiently accurate results than other methods.

The size of a damage zone will lead a proportional reduction of stiffness, which will also reflect to the mode shape curvature. So, the determination of crack size can be estimated by the amount of change in the mode shape curvature.

3 Explain the bending test result in comparison with the results from the following method:

(1) Vibration tests

(2) FEM calculation

Discuss the above result in term of stiffness and discuss the accuracy of using the beam bending equation to calculate the structural properties of the candle filter.

Seven ceramic candle filters, included five used Schumacher filters one new Schumacher filter and one new Refractron filter, were inspected by using the bending test. Static characterization using four-point bending analysis has been conducted on these filters, and finite element calculation was applied on one of B-group Schumacher filters. Consistent deflections have been determined for each of the filters. The average experimental deflection for Schumacher A-group filters is 0.0074-in, 0.0064-in for Schumacher B-group filters, 0.0062 for new Schumacher filter and 0.006-in for new Refractron filter. Schumacher A- 
group filters have greatest deflections among these filters, which indicates that Schumacher A-group filters have the lowest stiffness among these filters.

The Young's modulus values for these filters are shown as the following: Refractron (new) $\mathrm{E}=5.02 \times 10^{6} \mathrm{psi}$, Schumacher (new) $\mathrm{E}=4.8 \times 10^{6} \mathrm{psi}$, Schumacher B-group filters (460 hours) $E=4.3 \times 10^{6} \mathrm{psi}$, Schumacher A-group filters (1705 hours) $E=4.1 \times 10^{6} \mathrm{psi}$. The Young's Moduli obtained from the vibration tests are larger than the Young's Moduli obtained from the bending test. The percentage difference of Schumacher A-group filter between dynamic and static analysis is $16.3 \%$, and the difference for Schumacher B-group filters is $16.9 \%$, the differences for new Schumacher and Refractron filters are $17.2 \%$ and $17.7 \%$ respectively. The bending test results indicate that the stiffness of these filters did not agree well with the results from the vibration test.

The average deflection of B-group Schumacher filter in a four-point bending experimental test is 0.0065 -inch at the loading of $15 \mathrm{lb}$. It is taken the difference between 20.7 lb. and 35.7lb. From the FEM result, the deflection at the loading of $35.7 \mathrm{lb}$. is $0.0062 \mathrm{in}$. The deflection from experiment is much greater than the FEM result. The FEM deflection result using use a Young's modulus $\mathrm{E}=5.3 \times 10^{6} \mathrm{psi}$.

The deflections from experiment are much greater than the FEM result. So, it indicates that there are some effects during the bending test. In a circular cross section, the shear stress is not parallel to the shear force. So, at points of the cross section along the boundary, the shear stress is tangent to the boundary. The bending moment is considered to cause deflections, also additional deflection will be produced by the shearing force in the form of a mutual sliding of adjacent cross sections along each other and surrounding area. The following are the possibilities for causing the error of bending test: 
- Shear Effect — the area between bottom and top supports will perform shear effect, which will affect the deflection

- Rebound Effect — supports of bending test may rebound the filter when load applied.

- Spherical surface of support — it may cause the filter to move.

- Loading Frame — it vibrated the experimental setup when increasing load.

- Experimental Environment — the air conditioner at the laboratory room creates tremble environment.

- Accuracy of LVDT — the core of LVDT was glue on the center of filter, it may became shaking in a tremble environment. Also, its accuracy needs to be improved.

To assume there was a rebound affect from aluminum blocks, the four-point bending FEM simulation was reconstructed as Figure 7.2. Two bottom aluminum supports were considered as a spring. The stiffness of the aluminum support was about $19000 \mathrm{lb} / \mathrm{in}$ and the Young's modulus of this candle filter was assuming at $E=5.3 \times 10^{6} \mathrm{psi}$, when the FEM deflection is agreeable with the experimental measurement. 


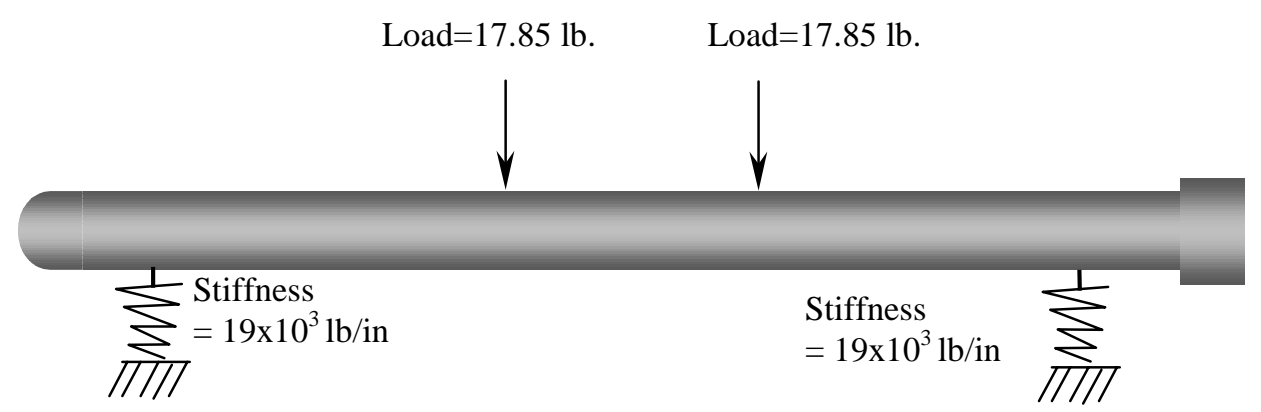

Figure 7.2 Four-Point Bending with Two Spring Supports

The center deflection of FEM using $35.7 \mathrm{lb}$. test with two spring supports was 0.0151 in. Using the result to recalculate the deflection of $15 \mathrm{lb}$. of load was $0.00635 \mathrm{in}$. It was close to the experimental result 0.0064 in. The tensile stress at the center was 170 psi. The difference between experimental result and FEM result with two spring supports is $0.78 \%$. So, it can be said that aluminum blocks perform rebound affect to the filters. The deflection of ceramic candle filter is always small and easily influenced by surrounding environments. In order to measure a small deflection, the experiment setup and lab environment need to be considered carefully. Though, the bending tests are not completely successful, the bending method seems to be able to correctly indicate the difference of stiffness degradation levels among these filters as shown in Figure 7.3. 


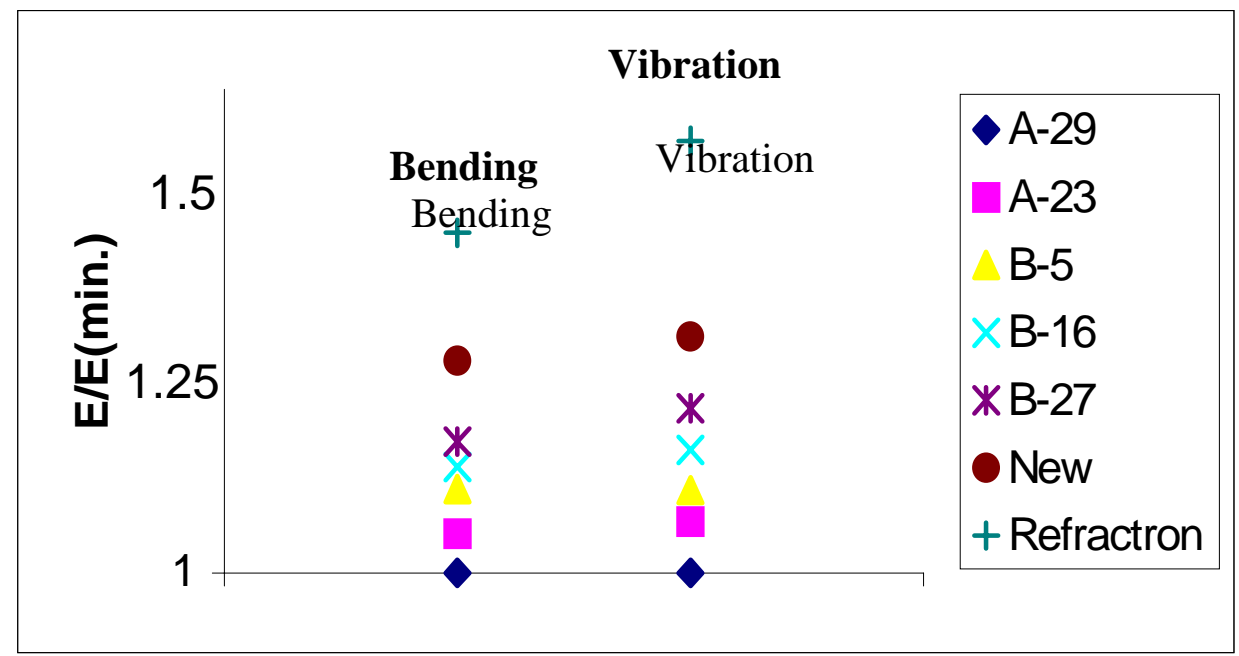

Figure 7.3 Degradation of Tested Filters From Bending and Vibration Test 


\section{CHAPTER 8}

\section{CONCLUSIONS AND RECOMMENDATION}

\subsection{Conclusions}

Static characterization using four-point bending test has been conducted on six Schumacher filters and one Refractron filter. The load-deflection curve has been determined for each of these filters. The Young's Moduli of used ceramic candle filters given by the four-point bending equation are $\mathrm{K}=2161 \mathrm{lb} / \mathrm{in}$ for A-group Schumacher filters and $\mathrm{K}=2297$ lb/in for B-group Schumacher filters. The Young's Moduli of the new Schumacher filter and the new Refractron filter are $\mathrm{K}=2542 \mathrm{lb} / \mathrm{in}$ and $\mathrm{K}=2586 \mathrm{lb} / \mathrm{in}$ respectively. The percentage difference between the new Schumacher filter and Schumacher filters used 460 hours is $10 \%$, and the percentage difference between the new Schumacher filter and Schumacher filters used 1705 hours is $15 \%$. This indicates that the static characterization method has sufficient sensitivity for degradation evaluation due to different operating hours.

Dynamic characterization using experimental modal analysis and finite element calculations has been conducted on a new Schumacher filter and a repaired Schumacher filter, which was broken into two pieces during the bending test and connected together by using epoxy glue. Vibration frequencies and mode shapes have been determined for these filters. The Young's modulus obtained for the new Schumacher filter is $E=5.85 \times 10^{6}$ psi. The other six filters, included A-group and B-group Schumacher filters and a new Refractron filter, had been previously tested using vibration analysis. The Young's moduli (E) values for these

filters are Refractron (new) E=6.88x106 psi; A-group filters (1705 hours) E= 4.9x106 psi; B- 
group filters (460 hours) E= 5.3x106 psi (Chen and Parthasarathy, 1996). The comparison of Young's moduli between the new Schumacher filter and Schumacher filters used 460 hours is about $10 \%$, and for the new Schumacher filter and Schumacher filters used 1705 hours is about $17 \%$.

The degradations from vibration and bending analyses are consistent. Though the bending test results can not give an accurate estimation of the Young's moduli of these filters, the bending test results can still reflect the change of the stiffness among the filters as the vibration test. From the results, it can be determined that ceramic candle filters used more hours have lower natural frequencies, which also indicate lower stiffness.

The frequencies of repaired A-4 Schumacher filter are higher than it was broken before. It can be caused by the strong material stiffness of epoxy glue. From the two mode shapes before it broken and after it repaired, there is a phase shift near the damage area. The occurrence of phase shift is because the structure of that area changed. So, the mode shapes can be used to detect the damage location by examining the phase shift.

\subsection{Recommendations for Future Research}

A vibrating motion on the ceramic candle filters performs not only vibration movements, but also shear effects and rotation. That is why the frequencies obtained from Bernoulli-Euler equation are higher than FEM results. Future research regarding the free-free vibration analysis should consider shear effects and rotation. To consider possible affects during a free-free vibration analysis, the Timoshenko equation can help to better understand the behavior of the ceramic candle filters. The head of PCB impact hammer used in this 
research is made of steel. There is a possibility for the impact hammer to produce damage to the surface of ceramic filters when knocking the filters. The head of impact hammer needs to be encompassed with rubber or other soft material, which will not harm the filters.

Future research regarding the bending test on the ceramic candle filters should conduct in a quiet environment. The deflection of ceramic candle filter is always small before it was broken. Any small influence may cause a small increase of deflection, but it will lead a big error difference in results. So, the experimental instruments and environment need to be considered carefully before testing in order to get accurate results. 


\section{REFERENCES}

1. Alvin, M.A., R.E. Tressler, T.E. Lippert, E.S. Diaz, and E.E. Smeltzer, "Durability of Ceramic Filters," Paper Presented at the Coal-Fired Power Systems 94 -- Advances In IGCC and PFBC Review Meeting, Morgantown, WV, pp. 545-571, June 21-23, 1994.

2. Alvin, M.A., "Porous Ceramic Hot Gas Filters -- Materials and Applications," Paper presented at the Proceedings of the 2nd International Conference on Heat-Resistant Materials, Gatlinburg, Tennessee, 11-14 September, 1995.

3. A. Kiriakidis, "Structural Properties Evaluation of Ceramic Candle Filter Using Vibration Response," Problem Report for MSCE at West Virginia University, 1998

4. Chen, H.L., Spyrakos, C.C., Venkatesh, G., "Evaluating Structural Deterioration by Dynamic Response," Journal of Structural Engineering, Vol. 121, No.8, pp.1197-1204, August 1995.

5. Chen, H. L., Parthasarathy, B., "Nondestructive Evaluation of Ceramic Candle Filters at Varying Degradation," Proceedings of the First US-Japan Symposium on Advanced in NDT, ASNT, June, 1996.

6. Chen, H. L., Parthasarathy, B., "Nondestructive Degradation Evaluation of Ceramic Candle Filters Using Vibration Signatures," Proceeding of Advanced Coal-Fired Power Systems'96 Review Meeting, July, 1996.

7. Chen, H. L., Parthasarathy, B., "Evaluating Structural Deterioration of Ceramic Candle Filters Using Dynamic Response", Proceeding of Pittsburgh Coal Conference, September, 1996.

8. Chen, H.L., Kiriakidis, A. and Peng, W., "Nondestructive Evaluation of Ceramic Candle Filters Using Vibration Response", Advanced Coal-Based Power and Environmental Systems '97 Conference, Pittsburgh, July 1997.

9. Chung-Kwei Lin, " Investigation of Mechanical Properties Variations in Thermal Spray Coatings " Ph.D. 1995.

10. C. Farrar, D. Jauregui, " Damage Detection Algorithms Applied to Experimental and Numerical Modal Data from I-40 Bridge" Los Alomos National Laboratory, NM, January 1996. 
11. Fumiko Sugiyama, Kinya Ogawa, "Impact Bending Test on Fiber-Reinfo ce Ceramics Aided by Multichannel High-Speed Digital Equipment," Trans. of the JSME, Vol.62, No.598, Ser.A, pp.1506-1512, 1996.

12. Fumiko Sugiyama, Kinya Ogawa," A New Application of Split-Hopkinson Bar to Impact Bending Test on Advanced Brittle Materials",Plasticity and Impact Mechanics, N.K. Gupta, pp.466-483(1996), New Delhi, India

13 J.E. Shigley, Charles R. Mischke, " Mechanical Engineering Design", fifth edition, McGraw-Hill, Inc., New York, NY, 1989.

14. J.M. Gere and S.P. Timoshenko, "Mechanics of Materials", $3^{\text {rd }}$ Ed, PWS-Kent, 1990.

15. Mindness, S., 1991, " Acoustic Emissions Methods", Handbook on Non-destructive Testing of Concrete, Ed. Malhotra, V.M., Cario, N.J., CRC Press, Chapter 14, 317 333.

16. Filter Element Workshop, Power System Development Facility, November 4-5,1998

17. Spain, J.D., Starrett, H.S., Southern Research Institute, "Physical, Mechanical, and Thermal Properties of Schumacher SiC filter material ," Report to U.S. Department of Energy, Morgantown Energy Technology Center, April 1994.

18 Stringer, J., Leitch, A.J., "Ceramic Candle Filter Performance at the Grimethorpe (UK) Pressurized Fluidized Bed Combustor," Journal of Engineering for Gas Turbines and Power, vol. 114, pp. 371-379, April 1992.

19. S. Timoshenko, D.H.Young, W.Weaver,JR.,"Vibration Problems In Engineering" Fourth Edition, 1974.

20. S. Timoshenko, D.H.Young, "Theory of Structure" Second Edition, 1965

21. Van Nostrand Reinhold,"Element of Strength of Material" 1968

22. Wai-Fah Chen, Shouji Toma, "Analysis and Software of Cylindrical Members" LoadDeflection Relation Ch.3, 1995.

23. Yun-Biao Xin, K. Jimmy Hsia," A Technique to Generate Straight Surface Cracks for Studying the Dislocation Nucleation Condition in Brittle Materials",TAM Report No.785 from University of Illinois at Urbana-Champaign, February 1995. 


\section{APPENDIX A}

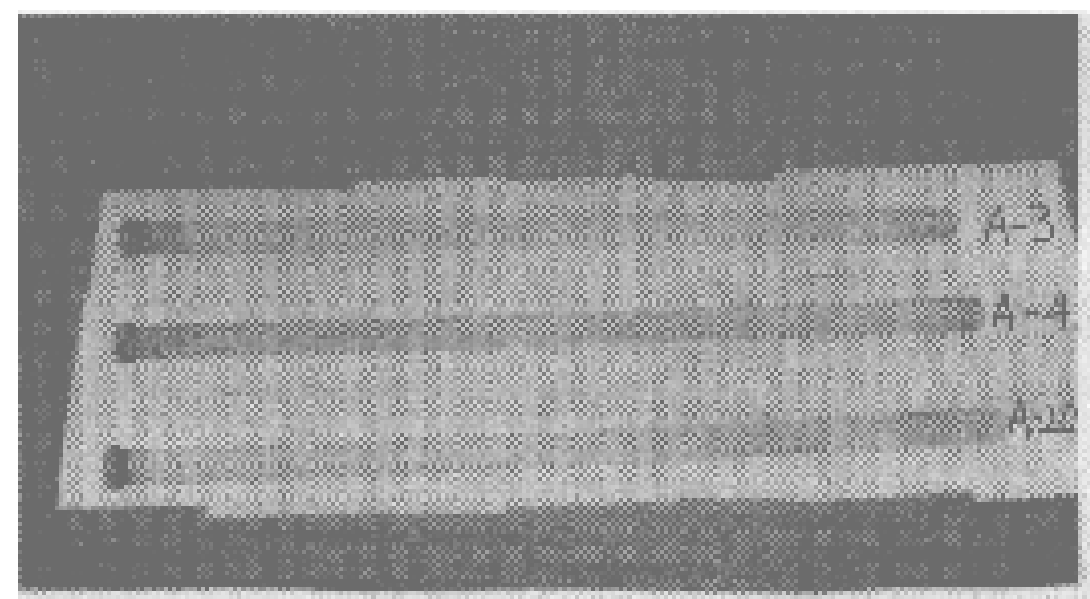

Figure A.1 Picture of Schumacher Filters \# A-3, A-4, A-20

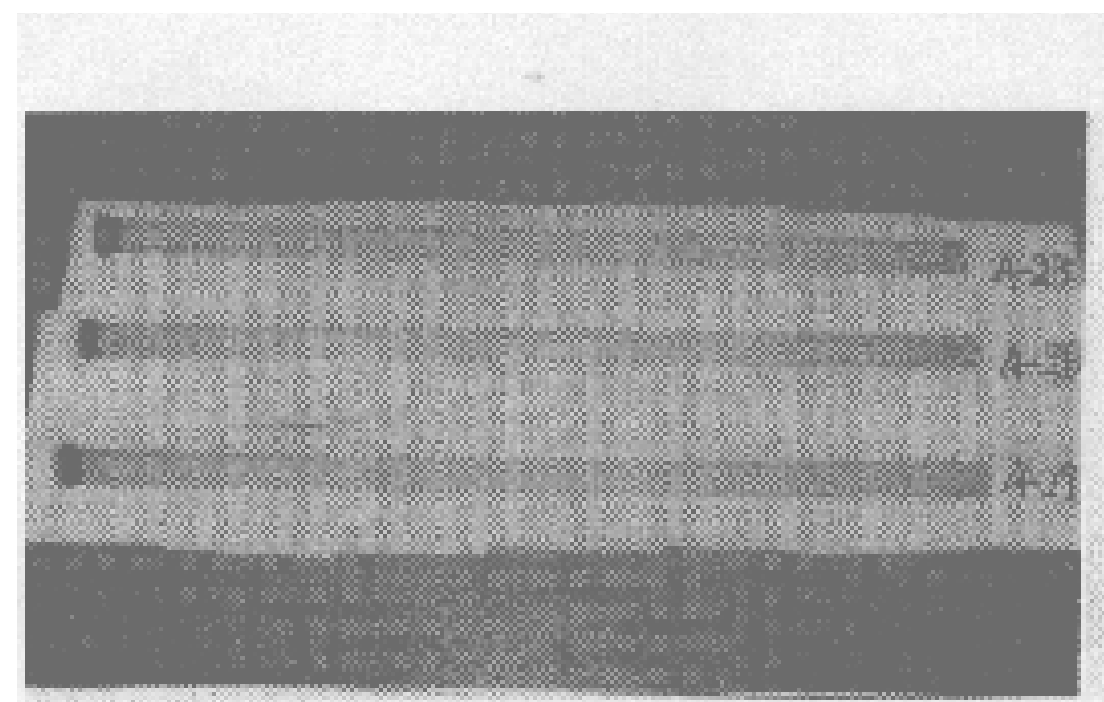

Figure A.2 Picture of Schumacher Filters \# A-23, A-26, A-29 


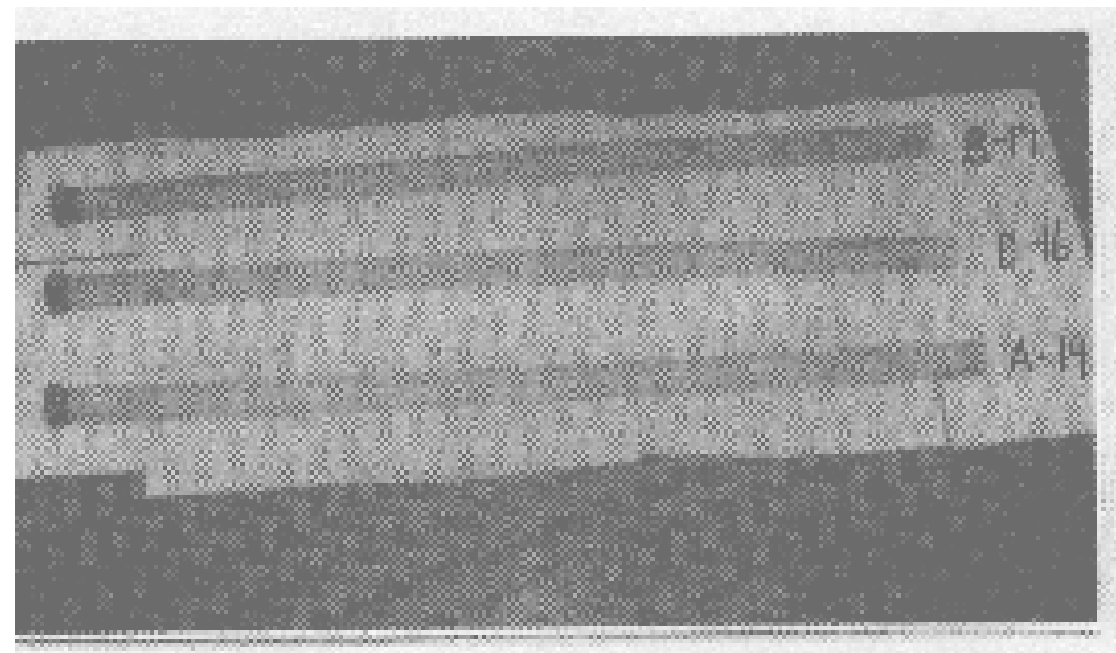

Figure A.3 Picture of Schumacher Filters \# B-16, B-19, A-19

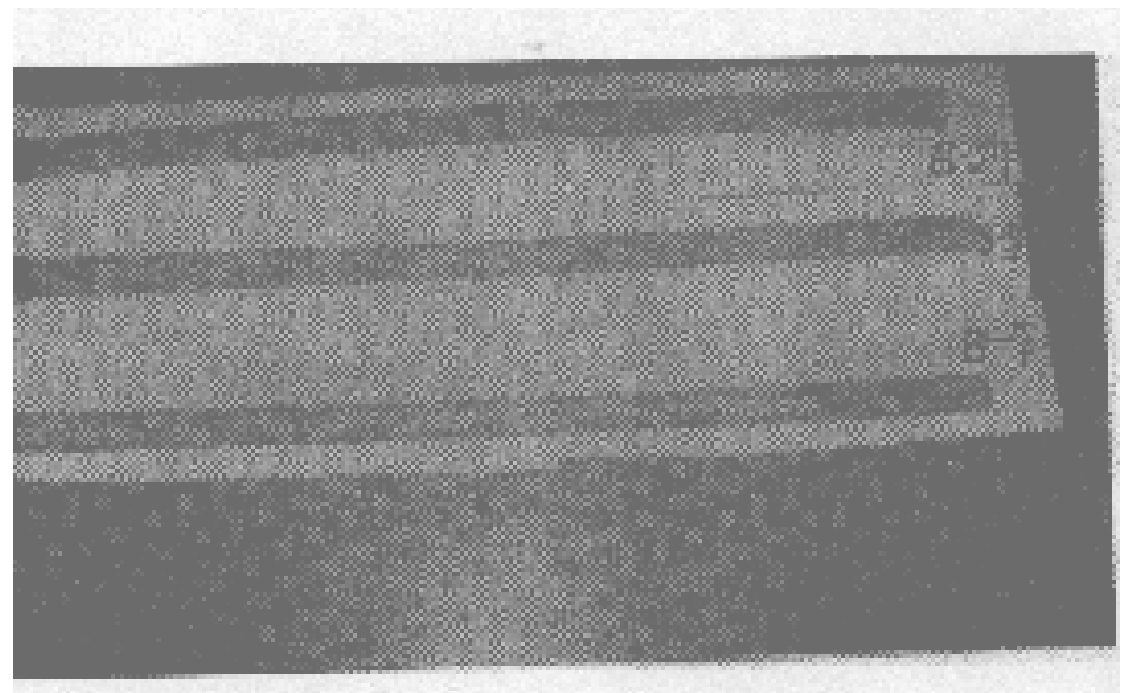

Figure A.4 Picture of Schumacher Filters \# B-5, B-7, B-27 


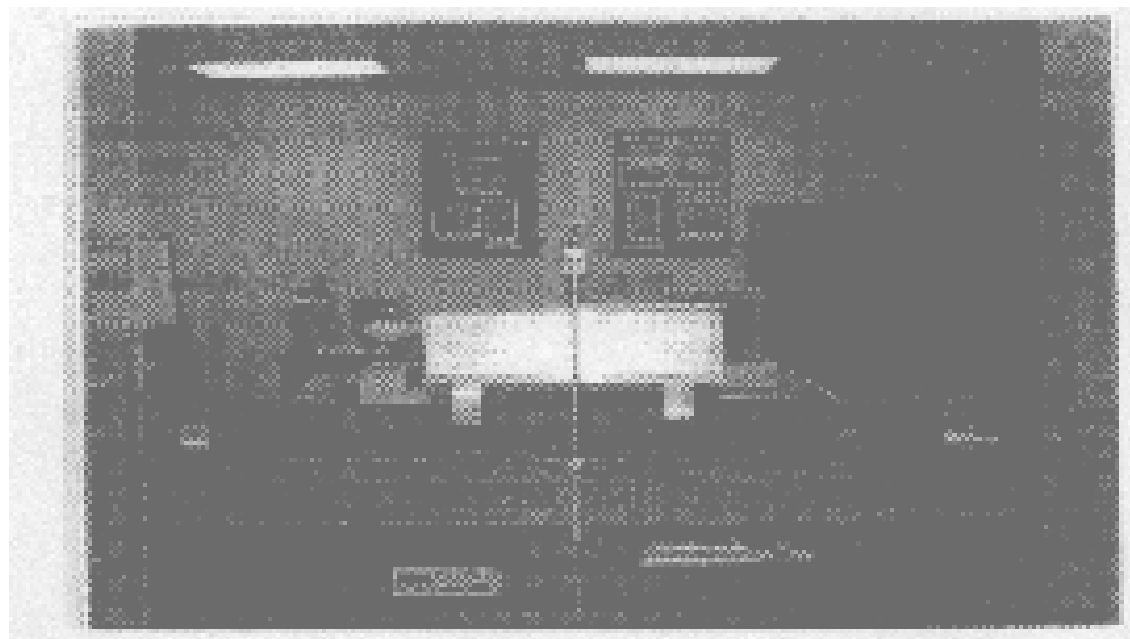

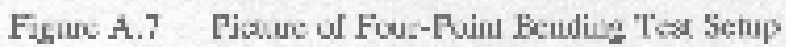

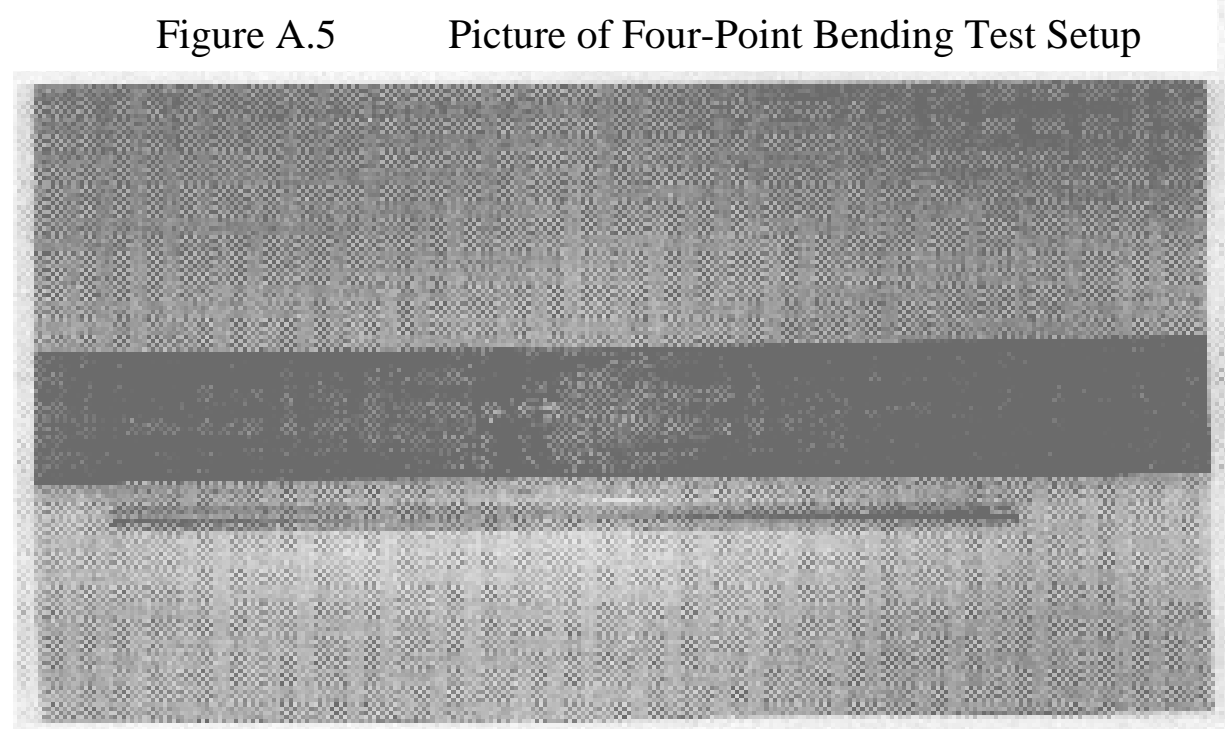

Figure A.6

Picture of Repaired A-4 Schumacher Filter 